\title{
Magnetization and Specific Absorption Rate Studies of Ball-Milled Iron Oxide Nanoparticles for Biomedicine
}

\author{
P. Burnham, ${ }^{1}$ N. Dollahon, ${ }^{2}$ C. H. Li, ${ }^{3}$ A. J. Viescas, ${ }^{1}$ and G. C. Papaefthymiou ${ }^{1}$ \\ ${ }^{1}$ Department of Physics, Villanova University, Villanova, PA 19085, USA \\ ${ }^{2}$ Department of Biology, Villanova University, Villanova, PA 19085, USA \\ ${ }^{3}$ Department of Mechanical Engineering, Villanova University, Villanova, PA 19085, USA
}

Correspondence should be addressed to G. C. Papaefthymiou; gcp@villanova.edu

Received 24 June 2013; Accepted 29 July 2013

Academic Editor: John Zhanhu Guo

Copyright (C) 2013 P. Burnham et al. This is an open access article distributed under the Creative Commons Attribution License, which permits unrestricted use, distribution, and reproduction in any medium, provided the original work is properly cited.

\begin{abstract}
Comparative studies are presented of iron oxide nanoparticles in the 7-15 $\mathrm{nm}$ average diameter range ball milled in hexane in the presence of oleic acid. Transmission electron microscopy identified spherical particles of decreasing size as milling time and/or surfactant concentration increased. Micromagnetic characterization via Mössbauer spectroscopy at room temperature yielded broadened magnetic spectroscopic signatures, while macromagnetic characterization via vibrating sample magnetometry of 7$8 \mathrm{~nm}$ diameter particles showed largely superparamagnetic behavior at room temperature and hysteretic at $2 \mathrm{~K}$. Zero-field and field-cooled magnetization curves exhibited a broad maximum at $\sim 215 \mathrm{~K}$ indicating the presence of strong interparticle magnetic interactions. The specific absorption rates of ferrofluids based on these nanoparticle preparations were measured in order to test their efficacies as hyperthermia agents.
\end{abstract}

\section{Introduction}

Progress in the synthesis of nanoparticles with desired properties has allowed for their application in biomedicine. Research in nonsurgical means for cancer treatment is vigorously being pursued, in an effort to efficiently eradicate cancerous cells via chemical or physical processes without collateral damage to neighboring healthy tissue, most notably through the use of magnetic nanoparticles for targeted drug delivery and for localized heating by absorption of electromagnetic radiation [1-8]. Hyperthermia cancer treatment is possible due to the capabilities of manufactured nanoparticles. With the means of achieving subsingle-magnetic domain particle sizes through various physical and chemical methods [9-14], superparamagnetic particles in the form of ferrofluids can be attained. When subjected to a magnetic field whose direction alternates rapidly, ferrofluids can absorb electromagnetic energy, which is readily dissipated to their environment by Brownian (particle rotation) and Néel (moment reorientation) relaxation mechanisms [8]. In vitro studies indicate that these processes result in heat dissipation and an increase in local temperature. When experiments are replicated in vivo, elevated local temperatures of $40^{\circ} \mathrm{C}$ to $46^{\circ} \mathrm{C}$ can be achieved, adequate to induce cell death or cell ablation in tumor tissue $[5,15,16]$. Iron oxide nanoparticles are ideal for application to hyperthermia treatment as they are biocompatible even up to $250 \mathrm{mg} / \mathrm{kg}$ of body weight of direct injection [12]. The most prevalent nanoparticle systems considered for biomedical applications are based on maghemite $\left(\gamma-\mathrm{Fe}_{2} \mathrm{O}_{3}\right)$ and magnetite $\left(\mathrm{Fe}_{3} \mathrm{O}_{4}\right)$. In the bulk, these two iron oxides share the same spinel crystallographic structure containing tetrahedral and octahedral iron sublattices but differ in chemical composition; magnetite contains both ferric and ferrous ions, while maghemite contains only ferric ions. Both are ferrimagnets with Curie temperatures of $850 \mathrm{~K}$ for magnetite and $948 \mathrm{~K}$ for maghemite; magnetite has a larger saturation magnetization of $92-100 \mathrm{emu} / \mathrm{g}$ compared to $60-80 \mathrm{emu} / \mathrm{g}$ for maghemite $[17,18]$. However, the saturation magnetization is significantly reduced in small particles compared to the bulk due to finite-size effects [19]. In the form of small particles, it is often difficult to distinguish between the two phases due to the presence of defects and nonstoichiometry in their structures. 


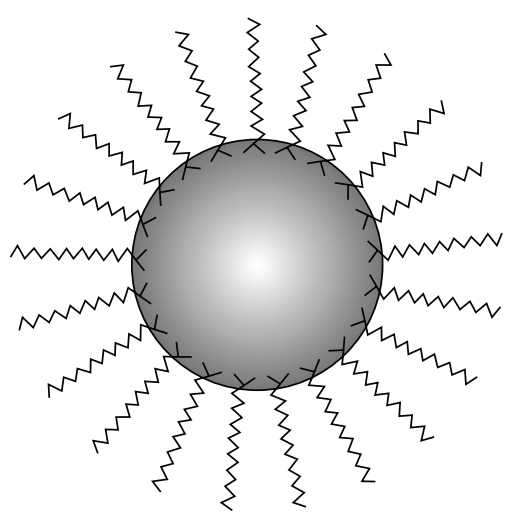

(a)

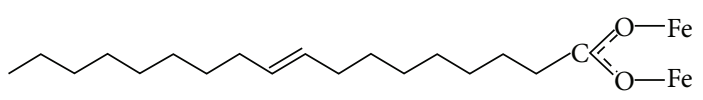

(b)

FIGURE 1: (a) Schematic representation of a sheath of surfactant molecules self-assembled around an iron oxide nanoparticle in an organic solvent. (b) Proposed bidentate interactions of the carboxylic head of oleic acid with iron ions on the surface of the nanoparticle.

Widespread use of iron oxide nanoparticles for biomedicine will depend on their broad availability, which will require cost-effective, mass production synthesis routes. We have, thus, tested commercially available nanoparticulate powders marketed as maghemite and magnetite in order to examine and compare their efficacies as hyperthermia agents. In order to produce uniform, that is, narrow nanoparticle-size distributions we utilized the process of surfactant assisted ball milling. Ball milling employs the use of grinding media in a mechanically oscillating mill, whereby repeated ball impacts result in the dissociation of microscopic portions of substance from a macroscopic sample [20, 21]. Both dry grinding and wet grinding are possible using a variety of carrier liquids. Ball milling has been suggested as a simple, low cost, and high yield means of reducing bulk into nanoparticles in an efficient "single-step" process [20]. Adding surfactants into the liquid environment in a milling process prevents cold welding and ensures a narrow size distribution [22]. Cold welding occurs when, due to prolonged grinding, nanoparticle surface energy becomes so high that contact with other particles results in the formation of larger, rather than smaller particle sizes, with increased milling time. Thus, normally, the lower limit of achievable particle size saturates with increased milling time [23].

Common liquid carriers employed in ball milling are hydrocarbons such as hexane $\left(\mathrm{CH}_{3}\left(\mathrm{CH}_{2}\right)_{4} \mathrm{CH}_{3}\right)$, while the most commonly used surfactant is oleic acid $\left(\mathrm{CH}_{3}\left(\mathrm{CH}_{2}\right)_{7} \mathrm{CH}=\mathrm{CH}\left(\mathrm{CH}_{2}\right)_{7} \mathrm{COOH}\right)$. Hexane is a relatively cheap, largely unreactive and easily evaporated nonpolar solvent. Surfactants are chain-like macromolecules with a polar, hydrophilic "head" and a nonpolar, hydrophobic "tail." The polar heads of the surfactant molecules adsorb onto the iron oxide nanoparticle surface, thus passivating the high surface energy, while the nonpolar tails extend into the hydrocarbon carrier liquid. Ideally, this results in the complete coating of each nanoparticle with a shell of surfactant molecules, as schematically depicted in Figure 1. The surfactants sterically isolate the particles from each other preventing cold welding and particle coagulation. In addition, the surfactants facilitate the coupling of individual magnetic particles with a substantial volume of the surrounding carrier liquid. At small enough particle sizes, this process leads to the formation of stable colloidal solutions. When a magnetic field is applied, the magnetic nanoparticle experiences a force in the direction of the magnetic field gradient. This force is also transmitted to the surrounding liquid, making the nanoparticle suspension behave as a magnetic fluid, coined a ferrofluid [25]. The thus produced ferrofluids are hydrophobic; to further functionalize them for in vivo applications, surfactant exchange processes must be employed to render the particles hydrophilic and thus biocompatible [26-28].

In this communication, morphological, Mössbauer, and magnetization studies of commercially marketed maghemite and magnetite nanopowders are presented. Narrow size distributions in the ca. $10 \mathrm{~nm}$ particle diameter regime were obtained by surfactant assisted High Energy Ball Milling (HEBM) [22]. One aim of the study was to assess the effect of milling time and surfactant concentration on the derived nanoparticle size distributions. Previous studies on ballmilled iron oxide nanoparticles have addressed the question of mean particle size as a function of milling time [21]. To our knowledge, the dependence of mean particle size on surfactant concentration has not previously been reported. A second aim of the study was to compare the efficacies of the two oxides as hyperthermia agents by carrying out in vitro studies of the specific-absorption-rate characteristics [29] of the derived ferrofluids as prepared from the commercially available powders.

\section{Materials and Methods}

Commercially produced (U.S. Research Nanomaterials, Inc., Houston, TX, USA), conglomerated $\gamma-\mathrm{Fe}_{2} \mathrm{O}_{3}$, (Stock \#: US3210) and $\mathrm{Fe}_{3} \mathrm{O}_{4}$ (Stock \#: US3220) powders in the 20$40 \mathrm{~nm}$ particle diameter regime were ground in a tungsten carbide holding canister with tungsten carbide milling media either dry for 7.5 hours or in hexane in the presence of oleic acid for various periods of time $(3 \mathrm{~h}, 6 \mathrm{~h}, 9 \mathrm{~h}$, and $12 \mathrm{~h}$ ). The canisters were oscillated in a SPEX SamplePrep 
$8000 \mathrm{M}$ (Metuchen, NJ, USA) mixer mill. Iron oxide samples of $10 \%$ mass to grinding media were first milled in hexane for one hour to disperse agglomerations of particles. Then, a specific concentration of oleic acid (OA) $(5 \%, 10 \%$, or $20 \%$, by mass to iron-oxide content) was added into the hexane environment and milled for varying amounts of time. After the milling process, particles were dried inside the tungsten carbide canister by allowing hexane to evaporate in air. They were then either crushed into powder for fourier transform infrared (FTIR) spectroscopy, Mössbauer spectroscopy, and magnetization measurements or redispersed in hexane for transmission electron microscopy (TEM) and specificabsorption-rate (SAR) measurements.

A fourier transform infrared spectrometer (Perkin-Elmer Co., Waltham, MA, USA) in attenuated-total-reflection mode was utilized to assess the chemical composition of the nanoparticles and confirm surfactant adhesion to the nanoparticle surface. Data was collected from $3750 \mathrm{~cm}^{-1}$ to $600 \mathrm{~cm}^{-1}$. A transition electron microscope (Hitachi H7600) operated at a voltage of $100 \mathrm{kV}$ was used to observe the dispersion, morphology and size distribution of the particles. The National Institutes of Health ImageJ software package was used to measure the diameters of about 150 to 200 nanoparticles of each sample preparation to provide statistical analysis of mean diameter and particle size distributions in the samples. Analysis of data showed that milling for six hours sufficiently reduced average particle size to levels comparable to those obtained in nine and twelve hours of milling.

Mössbauer spectroscopy in transmission geometry was performed at room temperature (RT) using a Ranger electronics constant-acceleration drive and a $20 \mathrm{mCi}{ }^{57} \mathrm{Co}$ radioactive source in Rh-matrix. The spectrometer was calibrated with a $6 \mu \mathrm{m}$ thick $\alpha$-Fe foil enriched in ${ }^{57} \mathrm{Fe}$. The WMOSS software package (SEE Co., Medina, MN, USA) was employed for spectral curve fitting. Isomer shifts $(\delta)$ are reported relative the metallic iron at RT. As purchased, dry $7.5 \mathrm{~h}$ milled and wet $6 \mathrm{~h}$ milled samples containing 5\%, $10 \%$, and $20 \%$ of oleic acid by mass of oxides were measured. Hyperfine parameters were determined for electronic and micromagnetic analysis.

A Physical Properties Measurement System (PPMS), equipped with a vibrating sample magnetometer (VSM) by Quantum Design (San Diego, CA, USA) capable of measurement from 2 to $400 \mathrm{~K}$ and in fields up to $90 \mathrm{kOe}$, was used to collect zero-field-cooled (ZFC) and field-cooled (FC) magnetization curves from $2 \mathrm{~K}$ to $400 \mathrm{~K}$ in an applied field of 200 Oe. In addition, isothermal magnetizations and hysteresis loops were collected at $300 \mathrm{~K}$ and $2 \mathrm{~K}$ for applied fields up to $20 \mathrm{kOe}$. One sample of $\mathrm{Fe}_{3} \mathrm{O}_{4}$ and one of $\gamma-\mathrm{Fe}_{2} \mathrm{O}_{3}$, both at $20 \%$ oleic acid, milled in hexane for 6 hours, were measured.

Specific absorption rate measurements were taken by placing a sample of $0.5 \mathrm{~mL}$ ferrofluid solution $(20 \%$ of ferrofluid in hexane by weight) in an alternating magnetic field created inside a water-cooled solenoid, as previously described [8]. An alternating current (AC) of $191.2 \mathrm{~A}$ amplitude and $282 \mathrm{kHz}$ frequency was used to generate an alternating magnetic field strong enough to cause combined

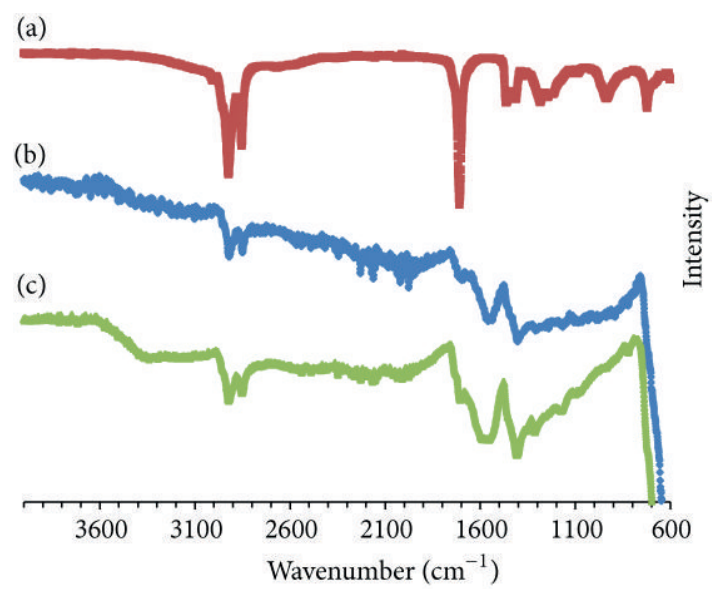

FIGURE 2: FTIR spectra of (a) oleic acid (OA), (b) magnetite nanoparticles coated with $\mathrm{OA}$, and (c) maghemite nanoparticles coated with OA.

Néel and Brownian relaxation [8] in the nanoparticle solution. An optical temperature sensor (Neoptix Nomad portable fiber optic thermometer) was placed inside the sample to record the temperature of the solution as a function of exposed time to the AC magnetic field. The initial slopes of sample-temperature versus time were analyzed to obtain the SAR of the ferrofluids according to [29]:

$$
\mathrm{SAR}=\left(\frac{c}{m_{\mathrm{Fe}}}\right) \cdot\left(\frac{\Delta T}{\Delta t}\right)_{\text {initial }} .
$$

Here $c$ is the sample specific heat capacity, which is calculated as a mass weighted mean value of the iron oxide particle/oleic-acid/hexane mixture, $m_{\mathrm{Fe}}$ is the iron mass fraction in the sample, $T$ is the temperature and $t$ is the time.

\section{Results and Discussion}

3.1. FTIR Spectroscopy. The FTIR spectra of oleic acid and oleic-acid covered $\gamma-\mathrm{Fe}_{2} \mathrm{O}_{3}$ and $\mathrm{Fe}_{3} \mathrm{O}_{4}$ nanoparticles are shown in Figure 2. The observed spectra are in agreement with those previously published by various investigators on these systems [30-32]. Sharp absorption lines are observed at characteristic wave numbers associated with various stretching modes present in the surfactant molecules. The iron oxide Fe-O stretching backbone vibrations, known to occur in the range of $520 \mathrm{~cm}^{-1}$ to $610 \mathrm{~cm}^{-1}$, do not fall within the range covered but are responsible for the sharp increase in absorbance at the lower limit of the horizontal axis at about $600 \mathrm{~cm}^{-1}$. The intense peak observed at $1710 \mathrm{~cm}^{-1}$ of the OA curve (Figure 2(a)) has been identified to derive from the $\mathrm{C}=\mathrm{O}$ stretch of the carboxylic head of the surfactant molecule. Its disappearance in the FTIR spectra of the OAcovered iron oxide nanoparticles indicates that the $\mathrm{OA}$ is strongly adsorbed or covalently bonded to the particle surface [30].

3.2. Transmission Electron Microscopy. Typical TEM micrographs of the ball-milled $\gamma-\mathrm{Fe}_{2} \mathrm{O}_{3}$ and $\mathrm{Fe}_{3} \mathrm{O}_{4}$ nanoparticles 


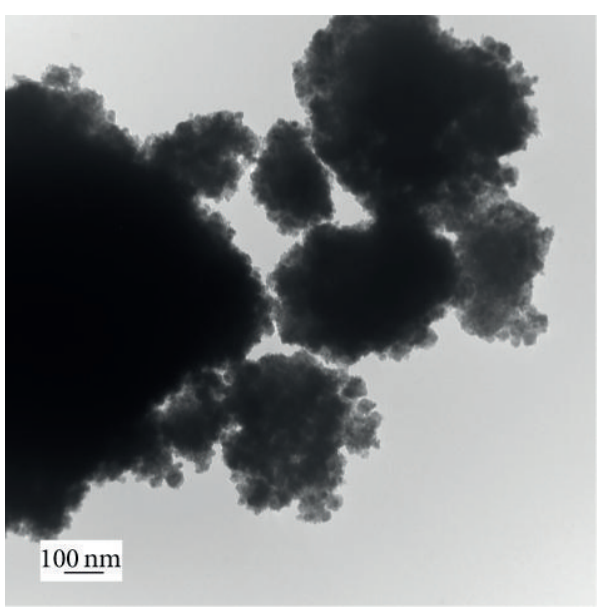

(a)

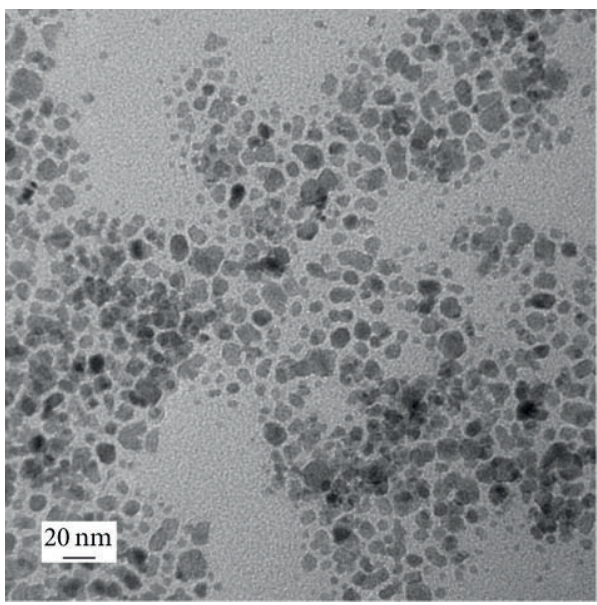

(c)

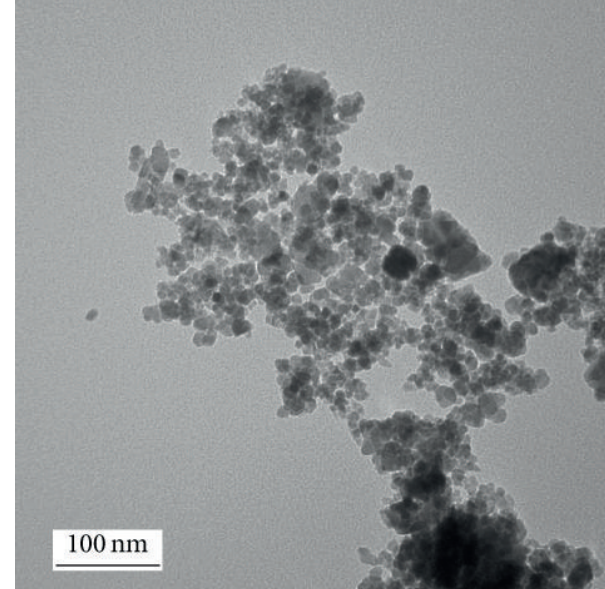

(b)

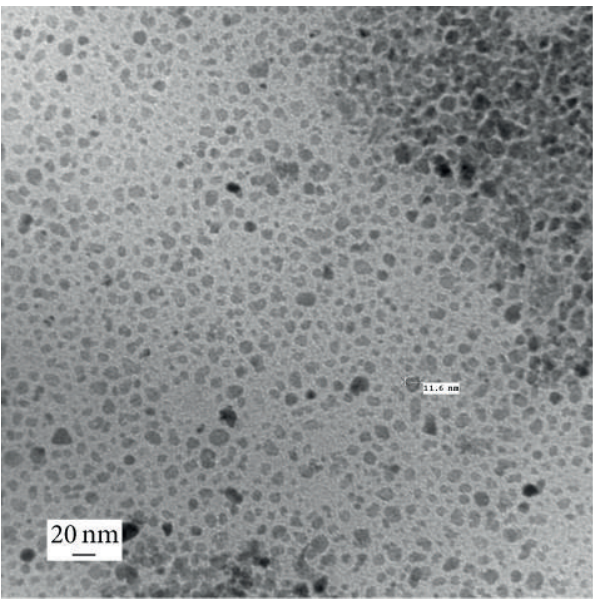

(d)

FIGURE 3: TEM micrographs of $\gamma$ - $\mathrm{Fe}_{2} \mathrm{O}_{3}$ nanoparticles for (a) dry milled (7.5 hrs) and wet milled (6 hrs) in hexane with (b) $5 \%$ OA, (c) $10 \%$ $\mathrm{OA}$, and (d) $20 \%$ OA by mass of hexane.

are shown in Figures 3 and 4, respectively. Initial observations indicated strongly that when a solution containing dry milled particles in the absence of oleic acid was dropped on a TEM grid, the nanoparticles were more disperse in total area on the grid and formed large aggregates up to 1 micron in size (Figures 3(a) and 4(a)). In addition to aggregates, isolated largediameter particles of relatively wide particle size distributions were found to be more prevalent in both oxide samples void of oleic acid, as seen in Figure 5(a) for the case of magnetite. When oleic acid was added, in both $\mathrm{Fe}_{3} \mathrm{O}_{4}$ and $\gamma-\mathrm{Fe}_{2} \mathrm{O}_{3}$ particle preparations, the width of the distribution of particle sizes became generally narrower and the average particle diameter was diminished for greater contents of oleic acid, as indicated in Figure 5(b). The presence of oleic acid results in drastically narrower distributions. Table 1 summarizes the results obtained from log-normal distribution analysis of the experimental data. It is observed that the mean particle diameters for either oxide decreased from $\sim 16 \mathrm{~nm}$ to $\sim 7 \mathrm{~nm}$ as surfactant concentration increased from $0 \%$ to $20 \%$ by mass of oleic acid to hexane (Figures 3(b)-3(d) and 4(b)-4(d)).
These diameters are well below the characteristic length scales for single-magnetic domain formation [33,34], as well as the critical size for superparamagnetism at room temperature for both oxides [35].

3.3. Mössbauer Spectroscopy. Figures 6 and 7 give the room temperature Mössbauer spectra for nanoparticles of $\gamma-\mathrm{Fe}_{2} \mathrm{O}_{3}$ and $\mathrm{Fe}_{3} \mathrm{O}_{4}$, respectively, milled for 7.5 hours dry (Figures 6(a) and $7(\mathrm{a}))$ and for 6 hours in hexane with various amounts of surfactant (Figures 6(b)-6(d) and 7(b)-7(d)). Even though, as established from TEM, all samples contain particles smaller than the critical size for superparamagnetism, no collapsed quadrupolar spectra are observed. The particle moments appear to be blocked; all spectra exhibit broadened magnetic hyperfine structure. This indicates the presence of sizable inter-particle magnetic interactions producing a magnetically frozen, spin-glass-like, state [36], which prevents thermal energies from inducing particle moment reversals within the characteristic measuring time for Mössbauer spectroscopy of $\sim 10 \mathrm{~ns}$. Nanoparticles in close proximity 


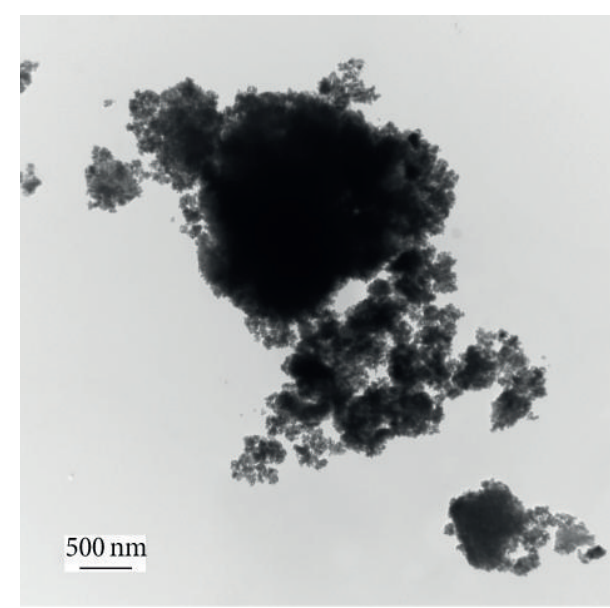

(a)

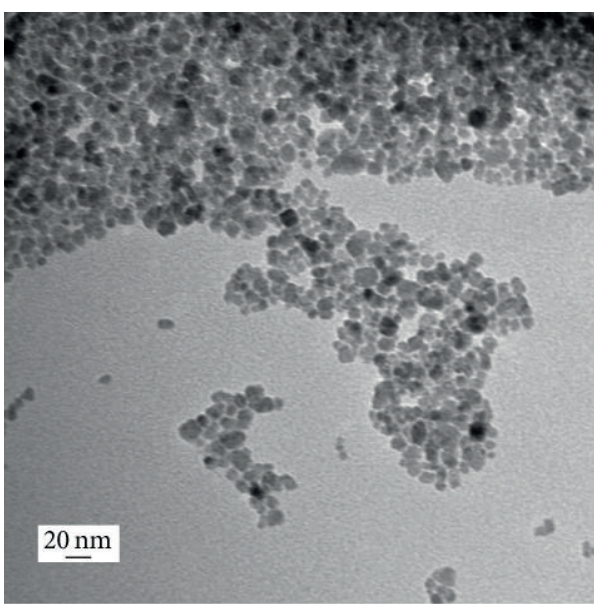

(c)

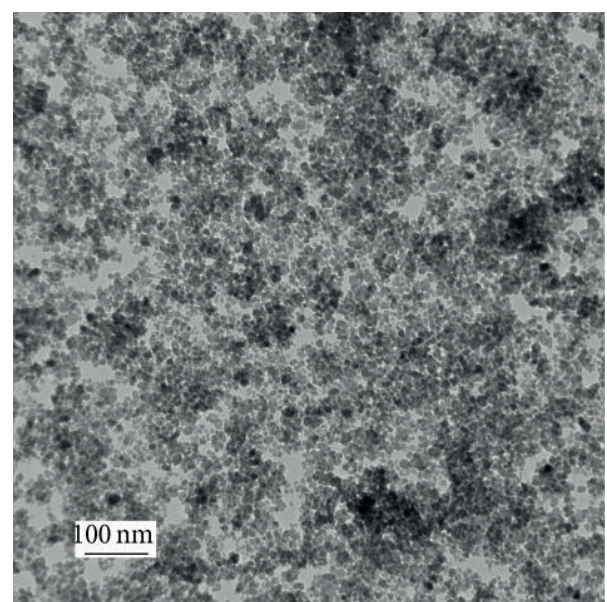

(b)

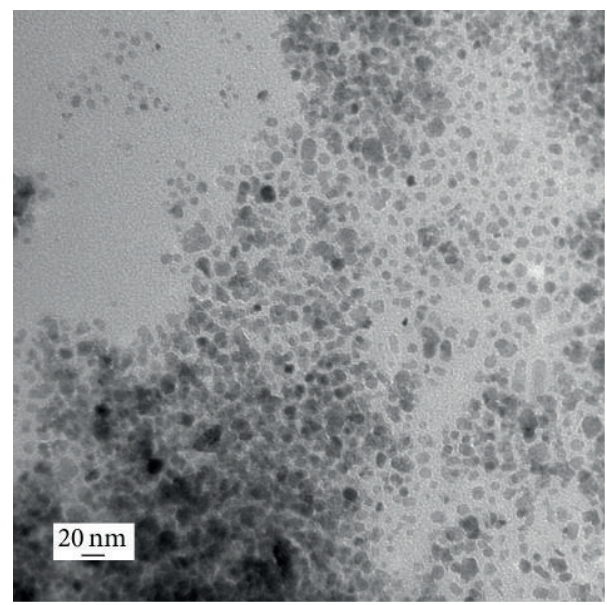

(d)

Figure 4: TEM micrographs of $\mathrm{Fe}_{3} \mathrm{O}_{4}$ nanoparticles for (a) dry milled (7.5 hrs) and wet milled (6 hrs) in hexane with (b) 5\% OA, (c) 10\% OA, and (d) $20 \%$ OA by mass of hexane.

TABLE 1: Morphological data of nanoparticles.

\begin{tabular}{lcccc}
\hline & \multicolumn{2}{c}{$\gamma-\mathrm{Fe}_{2} \mathrm{O}_{3}$} & \multicolumn{2}{c}{$\mathrm{Fe}_{3} \mathrm{O}_{4}$} \\
$\begin{array}{l}\text { Milling time, surfactant mass } \\
\text { percentage }\end{array}$ & Mean diameter (nm) & Standard deviation (nm) & Mean diameter (nm) & Standard deviation (nm) \\
\hline 7.5 hours, dry environment & 16.241 & 8.132 & 15.294 & 7.357 \\
6 hours, 5\% oleic acid in hexane & 13.674 & 5.137 & 10.747 & 3.442 \\
6 hours, 10\% oleic acid in hexane & 7.929 & 2.351 & 9.361 & 2.743 \\
6 hours, 20\% oleic acid in hexane & 7.287 & 2.394 & 7.967 & 2.073 \\
\hline
\end{tabular}

interact magnetically through two distinct mechanisms: (a) superexchange through grain boundaries and (b) dipoledipole interactions. The former is short-ranged and can occur only between bare magnetic nanoparticles in contact, while the latter is long-ranged and is present in most nanoparticle ensembles. Both interactions operate in the dry milled nanoparticle assemblies (Figures 6(a) and 7(a)), while only dipole-dipole interactions are operational between oleic-acid covered nanoparticles (Figures 6(b)-6(d) and 7(b)-7(d)). Dipole-dipole interactions become negligible only for large interparticle distances or diminished total particle magnetic moments, or macrospins, leading to the observation of superparamagnetism [36].

It is observed that the Mössbauer spectra for these commercially available iron oxide nanopowders are very similar. The most obvious difference is that the spectra of the $\mathrm{Fe}_{3} \mathrm{O}_{4}$ particles (Figure 7(a)) are broader, shallower, and less clearly defined than those of the $\gamma-\mathrm{Fe}_{2} \mathrm{O}_{3}$ particles (Figure 6(a)). Some of the additional broadening may be attributed to the coexistence of ferric $\left(3 d^{5}, \mathrm{Fe}^{3+}, \mathrm{S}=5 / 2\right)$ and ferrous 


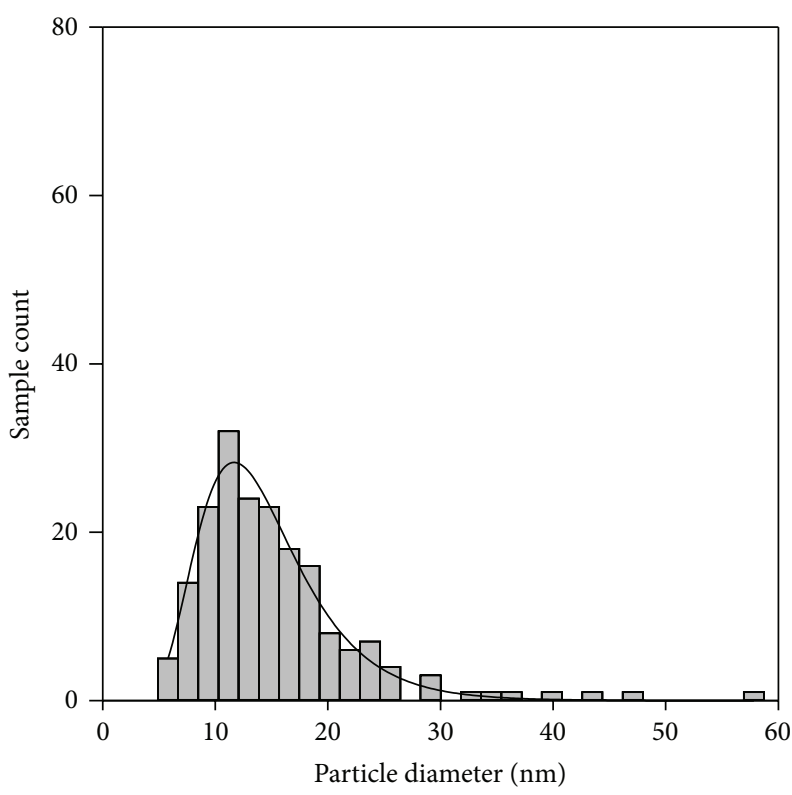

(a)

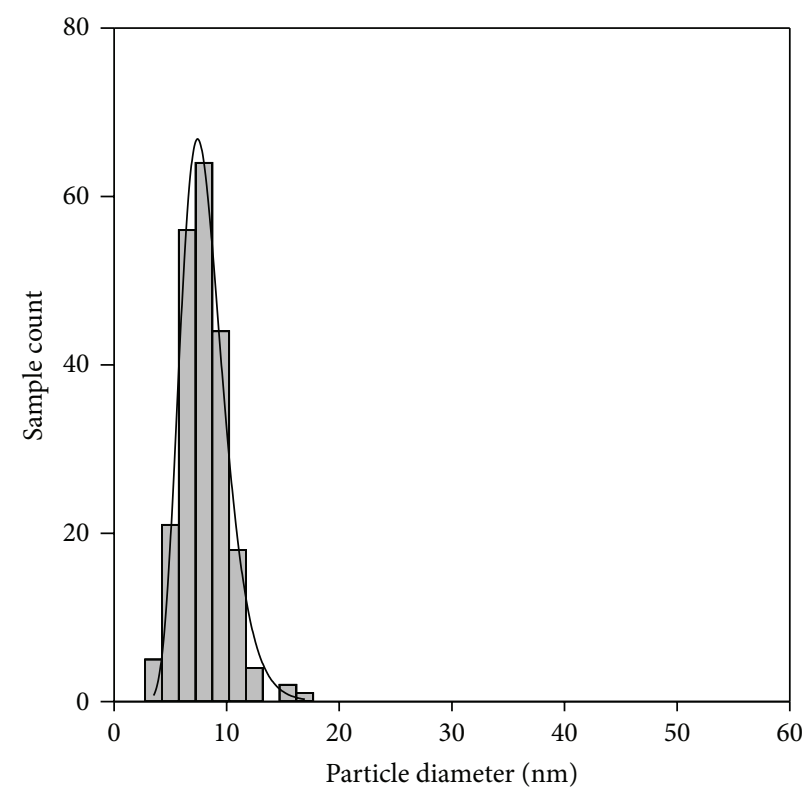

(b)

FIGURE 5: Particle size distributions for magnetite nanoparticles (a) milled dry for 7.5 hrs and (b) milled in hexane with $20 \%$ OA by mass of oxide. The solid line is a log-normal distribution fit to the experimental data (Table 1).

$\left(3 d^{6}, \mathrm{Fe}^{2+}, \mathrm{S}=2\right)$ ions in magnetite, as opposed to the occurrence of only ferric ions in maghemite. In the bulk, the two oxides share the same spinel crystallographic structure of antiparallel spin sublattices $(\mathrm{A} \uparrow)[\mathrm{B} \downarrow][\mathrm{B} \downarrow] \mathrm{O}_{4}$, where $(\mathrm{A})$ represents tetrahedral and $[\mathrm{B}]$ octahedral iron coordination to oxygen ions, and the vertical arrows depict the relative iron ion spin orientation. A strong antiferromagnetic interaction between (A) and [B] sublattices results in an overall ferrimagnetic order, rendering strongly magnetized particles. In the bulk the two oxide compositions can be represented by the formulas $\gamma-\mathrm{Fe}_{2} \mathrm{O}_{3} \rightarrow\left(\mathrm{Fe}^{3+}\right)\left[\mathrm{Fe}_{5 / 3}{ }^{3+} \square_{1 / 3}\right] \mathrm{O}_{4}{ }^{2-}$ (where $\square$ depicts iron vacancies in the spinel crystallographic structure) and $\mathrm{Fe}_{3} \mathrm{O}_{4} \rightarrow\left(\mathrm{Fe}^{3+}\right)\left[\mathrm{Fe}^{3+}\right]\left[\mathrm{Fe}^{2+}\right] \mathrm{O}_{4}{ }^{2-}$. At room temperature, there is fast electronic hopping of the sixth $3 d$ electron of the ferrous ion, $\left[\mathrm{Fe}^{3+} \leftrightarrow \mathrm{Fe}^{2+}\right]$, within the [B] sublattice, and the ${ }^{57} \mathrm{Fe}$ nucleus records an average valence of $\mathrm{Fe}^{2.5+}$. In stoichiometric bulk magnetite, room temperature Mössbauer spectra exhibit the superposition of two wellresolved, magnetic subspectra one for $\mathrm{Fe}^{3+}$ in (A) sites with isomer shift $\delta_{\mathrm{A}}=0.27 \mathrm{~mm} / \mathrm{s}$ and hyperfine field $H_{\mathrm{hfA}}=$ $491 \mathrm{kOe}$, and the other for $\mathrm{Fe}^{2.5+}$ in [B] sites with isomer shift $\delta_{\mathrm{B}}=0.66 \mathrm{~mm} / \mathrm{s}$ and hyperfine field $H_{\mathrm{hfB}}=453 \mathrm{kOe}$ with an intensity ratio $\left(\mathrm{Fe}^{3+}\right) /\left[\mathrm{Fe}^{2.5+}\right]=0.5[24]$. The corresponding Mössbauer parameters for bulk maghemite are $\delta_{\mathrm{A}}=0.27 \mathrm{~mm} / \mathrm{s}, H_{\mathrm{hfA}}=488 \mathrm{kOe}$ and $\delta_{\mathrm{B}}=0.41 \mathrm{~mm} / \mathrm{s}, H_{\mathrm{hfB}}=$ $499 \mathrm{kOe}$. In non-stoichiometric magnetite, a solid solution of $\mathrm{Fe}_{3-x} \mathrm{O}_{4-x}$ with $0 \leq x \leq 1$ may be present, ranging from maghemite, for $x=1$ with $(\mathrm{A}) /[\mathrm{B}]=0.6$ iron site occupancy ratio, to stoichiometric magnetite, for $x=0$ and $(\mathrm{A}) /[\mathrm{B}]=$ 0.5 . The presence of defects and vacancies associated with nonstoichiometry may slow down the electronic hopping time of the sixth $3 d$ electron [37] to the characteristic measuring time of $\sim 10 \mathrm{~ns}$ for Mössbauer spectroscopy and contribute to spectral broadening with concomitant loss of resolution of the $\mathrm{Fe}^{3+}$ and $\mathrm{Fe}^{2.5+}$ spectral signatures. In addition, nonstoichiometry results in an amorphous phase with fewer $\mathrm{Fe}^{2+}$ ions in the structure compared to stoichiometric magnetite as the particles are partially oxidized [37]. All these effects produced the severely broadened spectra seen in Figure 7. Particle size distributions, iron coordination distortion at defect sites and lower coordination at surface sites further broaden the spectral signatures in both oxides.

The spectra of dry milled maghemite nanoparticles (Figure 6(a)) present a relatively sharp magnetic signature. However, individual absorption lines deviate from simple Lorentzian shape, indicating a complex magnetic structure. The relative sharpness of the magnetic spectrum for $\gamma$ $\mathrm{Fe}_{2} \mathrm{O}_{3}$ nanoparticles milled dry in the absence of oleic acid (Figure 6(a)) is probably due to the large particle aggregates seen in the TEM micrographs of Figure 3(a). Without the oleic acid shell, a large fraction of the $\gamma-\mathrm{Fe}_{2} \mathrm{O}_{3}$ particles form micrometer size agglomerates with strongly interacting particles. The spectra were fit to the superposition of three subsites, two magnetic and one quadrupolar, indicated by turquoise, blue and red spectral signatures, respectively, in Figure 6(a). Table 2 gives the hyperfine parameters derived from the fits. The hyperfine magnetic field value of $499 \mathrm{kOe}$ at the [B] site is similar to that of bulk maghemite [24], while the hyperfine field of $438 \mathrm{kOe}$ in the (A) site is somewhat reduced from that in the bulk [24]. The small quadrupolar contribution of isomer shift, $\delta=0.34 \mathrm{~mm} / \mathrm{s}$, and quadrupole splitting, $\Delta E_{\mathrm{Q}}=0.84 \mathrm{~mm} / \mathrm{s}$, is consistent with fast relaxing, high spin $\mathrm{Fe}^{3+}$ ions, which we attribute to the smallest particles in the distribution exhibiting superparamagnetism due to their 


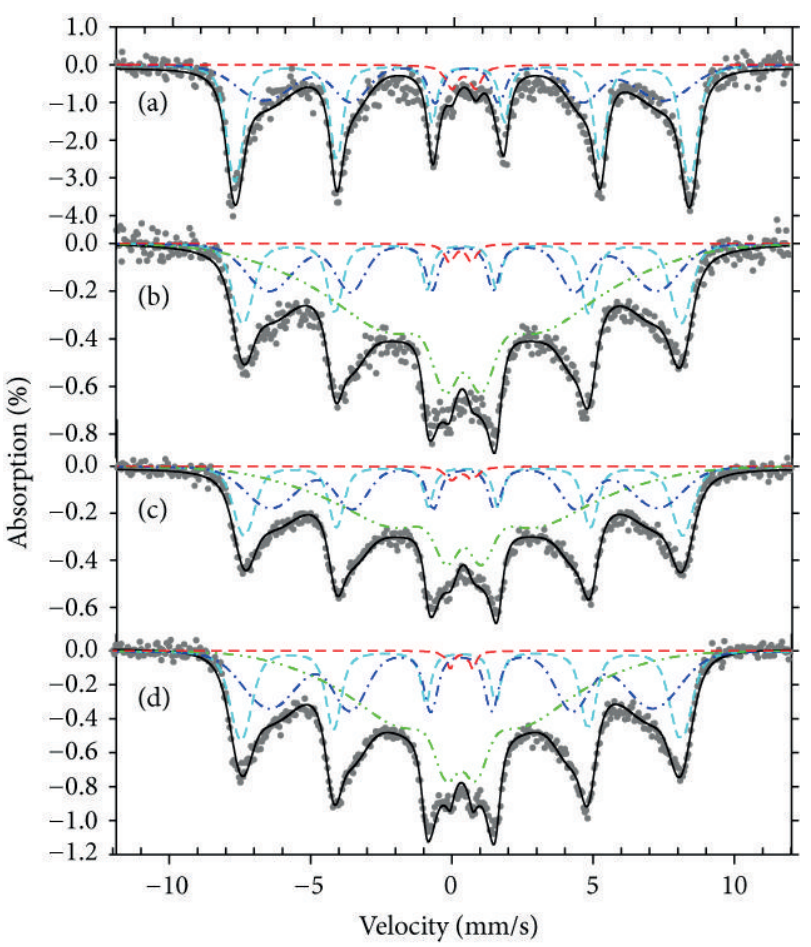

FIGURE 6: Room temperature Mössbauer spectra for $\gamma-\mathrm{Fe}_{2} \mathrm{O}_{3}$ nanoparticles (a) bare, dry milled for $7.5 \mathrm{hrs}, 16.2 \mathrm{~nm}$ diameter, and ((b)(d)) wet milled in hexane for $6 \mathrm{hrs}$ with various percent amounts of oleic acid by mass to hexane (b) $5 \%$ OA, $13.7 \mathrm{~nm}$, (c) $10 \%$ OA, $7.9 \mathrm{~nm}$, (d) $20 \% \mathrm{OA}, 7.3 \mathrm{~nm}$ diameter. The solid line through the experimental points is the least-square fit of the experimental data to a superposition of magnetic slow relaxation (turquoise and blue), superparamagnetic fast relaxation (red), and intermediate relaxation (green) spectral signatures indicated above the spectra (see text and Table 2).

diminished "macrospin" moments. In the presence of oleic acid and with decreasing particle size the spectra broaden (Figures 6(b)-6(d)). A similar tendency to broadening of dextran-coated versus bare magnetite nanoparticles has been previously reported [38].

All remaining spectra in Figures 6 and 7 were fit to the superposition of four iron subsites corresponding to (i) fast relaxing (A) and $[\mathrm{B}]$ sites with relaxation time $\tau_{s}<$ $10 \mathrm{~ns}$, giving rise to quadrupolar spectra (shown in red), (ii) slow relaxing $(\mathrm{A})$ and $[\mathrm{B}]$ sites with $\tau_{s}>10 \mathrm{~ns}$, giving rise to magnetically split, albeit broadened, spectra, (shown in turquoise and blue, resp.), and (iii) intermediately relaxing (A) and [B] subsites with $\tau_{s} \sim 10$ ns (shown in green). The Mössbauer spectra of the $\mathrm{Fe}_{3} \mathrm{O}_{4}$ particles are broad, even for the dry milled sample. Mössbauer hyperfine parameters and site or component identification of fitted spectral signatures for the $\gamma-\mathrm{Fe}_{2} \mathrm{O}_{3}$ nanoparticles are given in Table 2 and for $\mathrm{Fe}_{3} \mathrm{O}_{4}$ in Table 3. Data on the corresponding bulk oxides at room temperature are also given for comparison. In contrast to the case of maghemite, the larger hyperfine fields are identified with the (A) sites and the smaller ones with $[B]$ sites in magnetite. The generally reduced hyperfine fields for the nanoparticles compared to the bulk are due

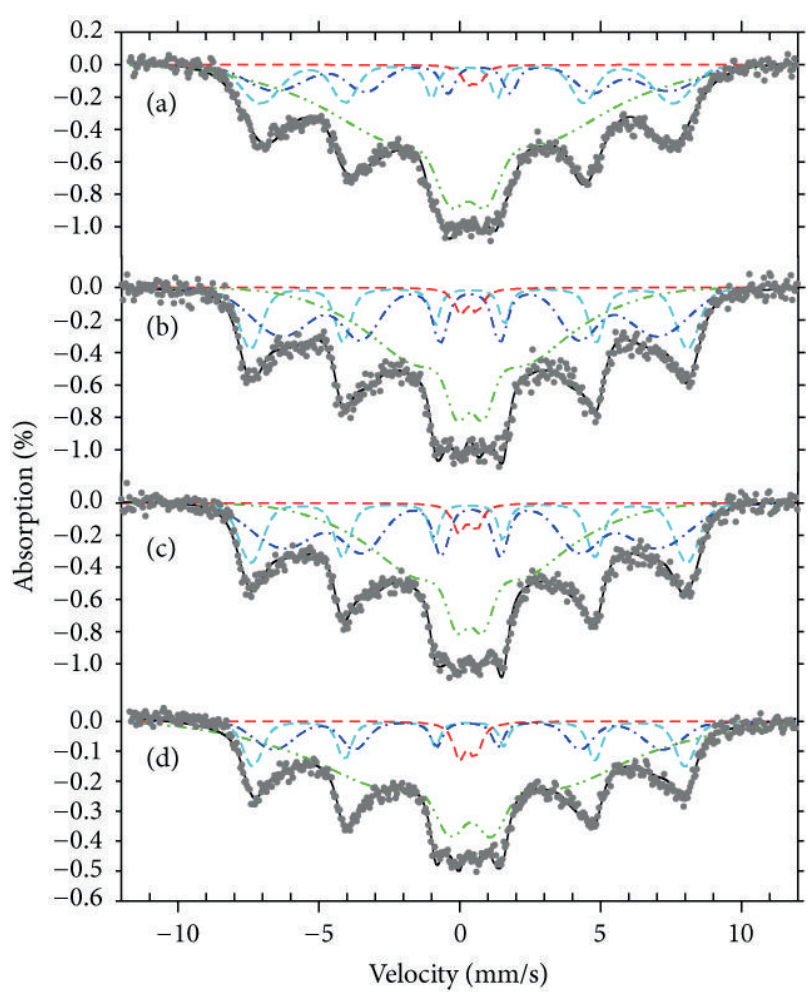

Figure 7: Room temperature Mössbauer spectra for $\mathrm{Fe}_{3} \mathrm{O}_{4}$ nanoparticles (a) bare, dry milled for $7.5 \mathrm{hrs}, 15.3 \mathrm{~nm}$ diameter and ((b)(d)) wet milled in hexane for $6 \mathrm{hrs}$ with various percent amounts of oleic acid by mass to hexane, (b) $5 \% \mathrm{OA}, 10.7 \mathrm{~nm}$, (c) $10 \%$ OA, $9.4 \mathrm{~nm}$, (d) $20 \% \mathrm{OA}, 8.0 \mathrm{~nm}$ diameter. The solid line through the experimental points is the least-square fit of the experimental data to a superposition of magnetic slow relaxation (turquoise and blue), superparamagnetic fast relaxation (red), and intermediate relaxation (green) spectral signatures indicated above the spectra (see text and Table 3).

to finite size effects. The consistently wider hyperfine field distributions $\left(\mathrm{DH}_{\mathrm{hf}}\right.$, full width at half maximum, FWHM, of the field distribution) of the magnetite versus the maghemite nanoparticles are attributed to nonstoichiometry and 6th $3 d$ electron delocalization in magnetite. With the exception of the bare $\gamma-\mathrm{Fe}_{2} \mathrm{O}_{3}$ nanoparticles, the largest contribution to the absorption area is that of the featureless intermediate relaxation (IR) component. We have used the parameters of the slow relaxing (SR) components to estimate $(\mathrm{A}) /[\mathrm{B}]$ ratios. Deviations of the $(\mathrm{A}) /[\mathrm{B}]$ ratios compared to the bulk oxides point to the presence of defects and site coordination distortion in the nanophase and a preponderance of (A) sites. It has previously been observed that surface sites in $\gamma$ - $\mathrm{Fe}_{2} \mathrm{O}_{3}$ nanoparticles behave more as (A) sites due to lower iron coordination number at the surface [36]. For particles of $\sim 10 \mathrm{~nm}$ diameter the surface to volume ratio is high with a large number of (A)-like surface sites.

3.4. VSM Magnetometry. Zero-field-cooled and field-cooled magnetization curves for the two oxides, milled for 6 hours in hexane at $20 \%$ oleic acid concentration at an applied field of 200 Oe, are presented in Figure 8. Data shown correspond 
TABLE 2: Mössbauer hyperfine parameters for $\gamma-\mathrm{Fe}_{2} \mathrm{O}_{3}$ nanoparticles measured at RT.

\begin{tabular}{|c|c|c|c|c|c|c|c|c|c|}
\hline Sample & $\begin{array}{c}\text { Particle } \\
\text { diameter }(\mathrm{nm})\end{array}$ & $\begin{array}{c}\text { Spectral } \\
\text { component }\end{array}$ & $\delta(\mathrm{mm} / \mathrm{s})$ & $\begin{array}{c}\Delta E_{\mathrm{Q}} \\
(\mathrm{mm} / \mathrm{s})\end{array}$ & $H_{\mathrm{hf}}(\mathrm{kOe})$ & $\begin{array}{l}\mathrm{D} H_{\mathrm{hf}} \\
(\mathrm{kOe})\end{array}$ & $A(\%)$ & $\begin{array}{c}\text { Component } \\
\text { identification }\end{array}$ & $\begin{array}{l}(\mathrm{A}) /[\mathrm{B}] \text { site } \\
\text { occupancy }\end{array}$ \\
\hline \multirow{3}{*}{$\begin{array}{l}\gamma-\mathrm{Fe}_{2} \mathrm{O}_{3} \\
\text { Bare }\end{array}$} & \multirow{3}{*}{16} & 1 & 0.39 & - & 499 & 28 & 52 & $\mathrm{SR}[\mathrm{B}]$ & \multirow{3}{*}{0.85} \\
\hline & & 2 & 0.33 & - & 438 & 129 & 44 & SR (A) & \\
\hline & & 3 & 0.34 & 0.84 & - & - & 4 & FR & \\
\hline \multirow{4}{*}{$\begin{array}{l}\gamma-\mathrm{Fe}_{2} \mathrm{O}_{3} \\
5 \% \mathrm{OA}\end{array}$} & \multirow{4}{*}{14} & 1 & 0.35 & - & 483 & 39 & 18 & SR [B] & \multirow{4}{*}{1.17} \\
\hline & & 2 & 0.30 & - & 427 & 105 & 21 & SR (A) & \\
\hline & & 3 & 0.38 & - & - & - & 60 & IR & \\
\hline & & 4 & 0.27 & 0.79 & - & - & 1 & FR & \\
\hline \multirow{4}{*}{$\begin{array}{l}\gamma-\mathrm{Fe}_{2} \mathrm{O}_{3} \\
10 \% \mathrm{OA}\end{array}$} & \multirow{4}{*}{8} & 1 & 0.39 & - & 482 & 41 & 22 & SR [B] & \multirow{4}{*}{1.14} \\
\hline & & 2 & 0.31 & - & 425 & 112 & 25 & SR (A) & \\
\hline & & 3 & 0.35 & - & - & - & 51 & IR & \\
\hline & & 4 & 0.27 & 0.75 & - & - & 2 & FR & \\
\hline \multirow{4}{*}{$\begin{array}{l}\gamma-\mathrm{Fe}_{2} \mathrm{O}_{3} \\
20 \% \mathrm{OA}\end{array}$} & \multirow{4}{*}{7} & 1 & 0.40 & - & 482 & 42 & 22 & SR [B] & \multirow{4}{*}{1.36} \\
\hline & & 2 & 0.29 & - & 420 & 122 & 30 & SR (A) & \\
\hline & & 3 & 0.33 & - & - & - & 47 & IR & \\
\hline & & 4 & 0.35 & 0.80 & - & - & 2 & FR & \\
\hline \multirow{2}{*}{${ }^{*}$ Bulk $\gamma-\mathrm{Fe}_{2} \mathrm{O}_{3}$} & & 1 & 0.41 & - & 499 & - & & {$[\mathrm{B}]$} & \multirow{2}{*}{0.60} \\
\hline & & 2 & 0.27 & - & 488 & - & & (A) & \\
\hline
\end{tabular}

Isomer shifts, $\delta$ : referenced to metallic iron at RT (error: $\pm 0.03 \mathrm{~mm} / \mathrm{s}$ ), $\Delta E_{\mathrm{Q}}$ : quadrupole splitting (error: $\pm 0.05 \mathrm{~mm} / \mathrm{s}$ ), $H_{\mathrm{hf}}$ : average magnetic hyperfine field (error: $\pm 3 \mathrm{kOe}$ ), $\mathrm{DH}_{\mathrm{hf}}:$ FWHM of magnetic hyperfine field distribution, $A$ : absorption area (error: $\pm 5 \%$ ), SR: slow relaxation, FR: fast relaxation, IR: intermediate relaxation, (A): tetrahedral spinel site, and [B]: octahedral spinel site.

* Source [24].

TABLE 3: Mössbauer hyperfine parameters for $\mathrm{Fe}_{3} \mathrm{O}_{4}$ nanoparticles measured at RT.

\begin{tabular}{|c|c|c|c|c|c|c|c|c|c|}
\hline Sample & $\begin{array}{c}\text { Particle } \\
\text { diameter }(n m)\end{array}$ & $\begin{array}{c}\text { Spectral } \\
\text { component }\end{array}$ & $\delta(\mathrm{mm} / \mathrm{s})$ & $\begin{array}{c}\Delta E_{\mathrm{Q}} \\
(\mathrm{mm} / \mathrm{s})\end{array}$ & $H_{\mathrm{hf}}(\mathrm{kOe})$ & $\begin{array}{l}\mathrm{DH}_{\mathrm{hf}} \\
(\mathrm{kOe})\end{array}$ & $A(\%)$ & $\begin{array}{l}\text { Component } \\
\text { identification }\end{array}$ & $\begin{array}{l}\text { (A)/[B] site } \\
\text { occupancy }\end{array}$ \\
\hline \multirow{4}{*}{$\begin{array}{l}\mathrm{Fe}_{3} \mathrm{O}_{4} \\
\text { Bare }\end{array}$} & \multirow{4}{*}{15} & 1 & 0.33 & - & 470 & 51 & 18 & SR (A) & \multirow{4}{*}{0.47} \\
\hline & & 2 & 0.42 & - & 400 & 166 & 38 & SR [B] & \\
\hline & & 3 & 0.36 & - & - & - & 39 & IR & \\
\hline & & 4 & 0.32 & 0.61 & - & - & 5 & FR & \\
\hline \multirow{4}{*}{$\begin{array}{l}\mathrm{Fe}_{3} \mathrm{O}_{4} \\
5 \% \text { OA }\end{array}$} & \multirow{4}{*}{11} & 1 & 0.34 & - & 480 & 44 & 18 & SR (A) & \multirow{4}{*}{0.55} \\
\hline & & 2 & 0.39 & - & 413 & 143 & 33 & SR [B] & \\
\hline & & 3 & 0.37 & - & - & - & 47 & IR & \\
\hline & & 4 & 0.32 & 0.59 & - & - & 2 & FR & \\
\hline \multirow{4}{*}{$\begin{array}{l}\mathrm{Fe}_{3} \mathrm{O}_{4} \\
10 \%\end{array}$} & \multirow{4}{*}{9} & 1 & 0.32 & - & 479 & 47 & 18 & SR (A) & \multirow{4}{*}{0.53} \\
\hline & & 2 & 0.39 & - & 409 & 155 & 34 & $\mathrm{SR}[\mathrm{B}]$ & \\
\hline & & 3 & 0.36 & - & - & - & 45 & IR & \\
\hline & & 4 & 0.27 & 0.62 & - & - & 3 & FR & \\
\hline \multirow{4}{*}{$\begin{array}{l}\mathrm{Fe}_{3} \mathrm{O}_{4} \\
20 \%\end{array}$} & \multirow{4}{*}{8} & 1 & 0.30 & - & 474 & 37 & 14 & SR (A) & \multirow{4}{*}{0.87} \\
\hline & & 2 & 0.39 & - & 427 & 90 & 16 & SR [B] & \\
\hline & & 3 & 0.41 & - & - & - & 68 & IR & \\
\hline & & 4 & 0.29 & 0.62 & - & - & 3 & FR & \\
\hline \multirow{2}{*}{${ }^{*}$ Bulk $\mathrm{Fe}_{3} \mathrm{O}_{4}$} & & 1 & 0.27 & - & 491 & - & - & (A) & \multirow{2}{*}{0.5} \\
\hline & & 2 & 0.66 & - & 453 & - & - & [B] & \\
\hline
\end{tabular}

Isomer shifts, $\delta$ : referenced to metallic iron at RT (error: $\pm 0.03 \mathrm{~mm} / \mathrm{s}$ ), $\Delta E_{\mathrm{Q}}$ : quadrupole splitting (error: $\pm 0.05 \mathrm{~mm} / \mathrm{s}$ ), $H_{\mathrm{hf}}$ : average magnetic hyperfine field (error: $\pm 3 \mathrm{kOe}$ ), $\mathrm{DH}_{\mathrm{hf}}: \mathrm{FWHM}$ of magnetic hyperfine field distribution, $A$ : absorption area (error: $\pm 5 \%$ ), SR: slow relaxation; FR: fast relaxation, IR: intermediate relaxation, (A): tetrahedral spinel site, and [B]: octahedral spinel site.

${ }^{*}$ Source [24].

to $\gamma-\mathrm{Fe}_{2} \mathrm{O}_{3}$ nanoparticles with TEM-determined average diameter $\langle d\rangle=(7 \pm 2) \mathrm{nm}$ and $\mathrm{Fe}_{3} \mathrm{O}_{4}$ nanoparticles with $\langle d\rangle=(8 \pm 2) \mathrm{nm}$ (Table 1). Both particle ensembles exhibit a broad peak with $T_{\max } \sim 215 \mathrm{~K}$. The broad width of the ZFC peak is attributed to dipole-dipole interactions [36], since the particle size distribution is quite narrow as indicated by TEM measurements. The FC magnetizations remain relatively flat below $T_{\max }$. A kink observed at $\sim 41 \mathrm{~K}$ in the $\mathrm{FC}$ data of $\mathrm{Fe}_{3} \mathrm{O}_{4}$ particles may be associated with the Verwey transition which is known to be suppressed to lower temperatures in small particles compared to its value of $T_{V}=120 \mathrm{~K}$ in bulk $\mathrm{Fe}_{3} \mathrm{O}_{4}$ [24]. In agreement with the Mössbauer results, the overall characteristics of the ZFC/FC curves indicate the presence of interparticle magnetic interactions, which are known to shift 


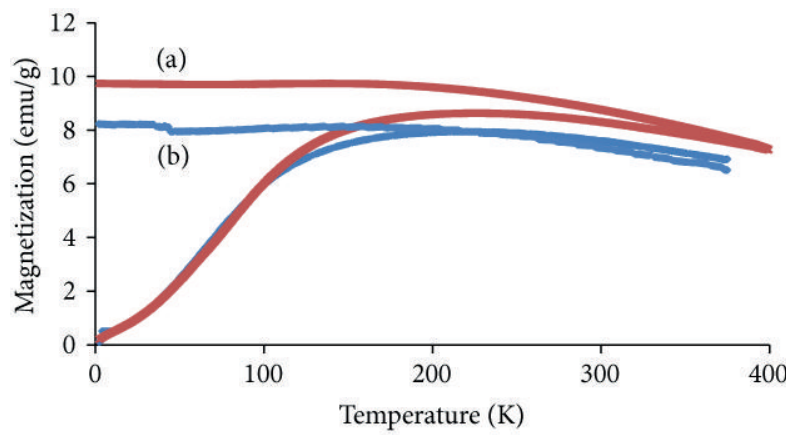

FIGURE 8: Zero-field-cooled and field-cooled magnetization curves of $6 \mathrm{hr}$ milled nanoparticles in hexane with $20 \%$ oleic acid (a) maghemite, and (b) magnetite at $H_{\text {appl }}=200$ Oe.

TABLE 4: Magnetic properties of nanoparticles in $20 \%$ oleic acid.

\begin{tabular}{lccc}
\hline & $\begin{array}{c}\text { Coercive field } \\
(\mathrm{Oe})\end{array}$ & $\begin{array}{c}\text { Saturation mag. } \\
(\mathrm{emu} / \mathrm{g})\end{array}$ & $\begin{array}{c}\text { Remnant mag. } \\
(\mathrm{emu} / \mathrm{g})\end{array}$ \\
\hline$\gamma-\mathrm{Fe}_{2} \mathrm{O}_{3}, 2 \mathrm{~K}$ & 680 & 37.500 & 16.114 \\
$\mathrm{Fe}_{3} \mathrm{O}_{4}, 2 \mathrm{~K}$ & 731 & 32.870 & 14.283 \\
$\gamma-\mathrm{Fe}_{2} \mathrm{O}_{3}, 300 \mathrm{~K}$ & 55 & 32.100 & 2.450 \\
$\mathrm{Fe}_{3} \mathrm{O}_{4}, 300 \mathrm{~K}$ & 55 & 29.325 & 2.260 \\
\hline
\end{tabular}

the blocking temperatures of isolated superparamagnetic particles to higher temperatures [36]. This effect has explicitly been demonstrated for ball-milled magnetite nanoparticles, where $T_{\max }$ in the ZFC curve decreases with the degree of nanoparticle dilution in an organic liquid $\left(\mathrm{CH}_{3} \mathrm{OH}\right)$ [21]. Surprisingly, the maghemite assembly in the applied field of 200 Oe exhibits larger magnetization $(\sim 9.82 \mathrm{emu} / \mathrm{g})$ than magnetite $(\sim 8.18 \mathrm{emu} / \mathrm{g})$. This observation persists in large applied fields presented below.

Isothermal magnetization data of the two oxides at $300 \mathrm{~K}$ and $2 \mathrm{~K}$ are shown in Figures 9 and 10, respectively. At $2 \mathrm{~K}$ both samples show symmetric hysteresis loops with coercivities of 680 Oe and 731 Oe for $\gamma$ - $\mathrm{Fe}_{2} \mathrm{O}_{3}$ and $\mathrm{Fe}_{3} \mathrm{O}_{4}$, respectively, while at $300 \mathrm{~K}$ they exhibit largely superparamagnetic behavior. Derived magnetic parameters, coercivities, saturation magnetizations, and remnant magnetizations are gathered in Table 4 . The data is comparable to previously reported values for similarly sized particles [21,39]. Upon expansion of the $x$-axis, it is noticed that actually at $300 \mathrm{~K}$ the data shows the onset of hysteretic behavior (Figure 9(c), Table 4). The observation of a small coercive field $(\sim 55 \mathrm{Oe})$ at room temperature indicates that interparticle interactions among some of the larger particles, or possibly partially coated particles, in the distribution are of the order of ambient thermal energies [40]. The saturation magnetizations, $M_{s}$, are severely reduced ( $35 \mathrm{emu} / \mathrm{g}$ ) compared to the corresponding bulk materials. This is a general feature of small magnetic particles where spin canting at the surface results in reduced, unsaturated magnetizations. This effect is often referred to as arising from the existence of a magnetically "dead layer" at the surface $[41,42]$. As seen in Table 4 the maghemite sample has a higher saturation magnetization $(37.50 \mathrm{emu} / \mathrm{g})$ compared

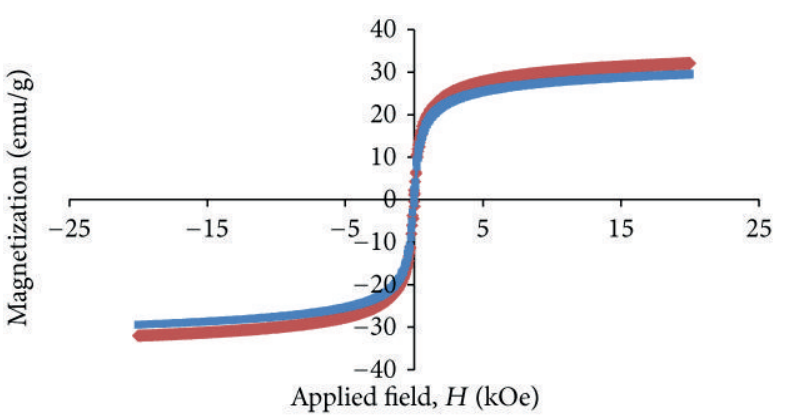

(a)

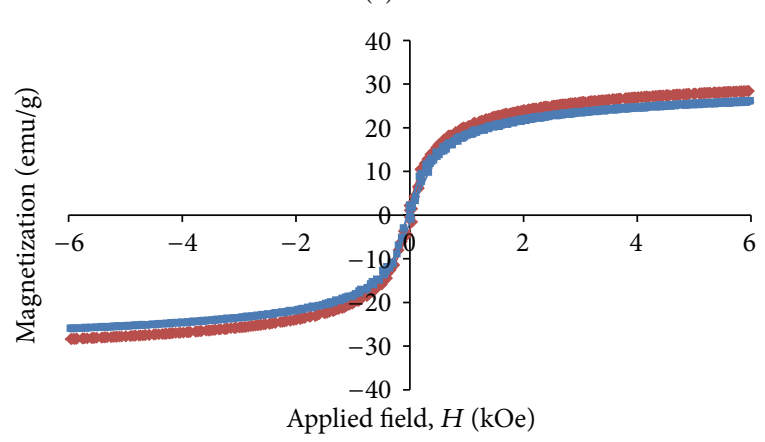

(b)

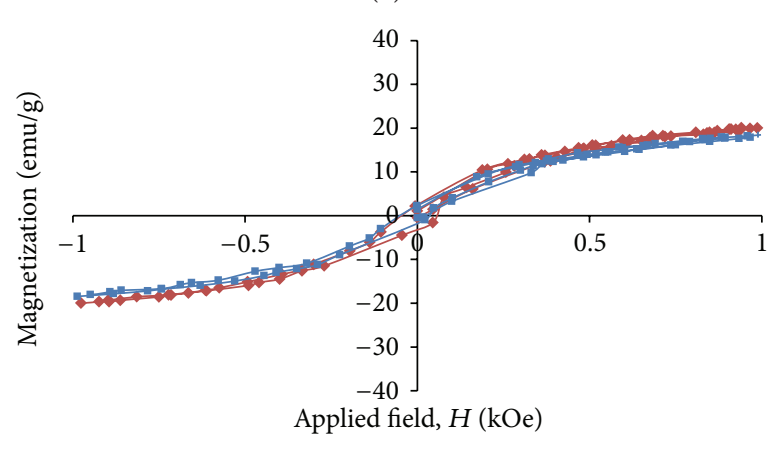

(c)

FIGURE 9: (a) Room temperature magnetization data for $\gamma-\mathrm{Fe}_{2} \mathrm{O}_{3}$ (red) and $\mathrm{Fe}_{3} \mathrm{O}_{4}$ (blue) nanoparticles milled with $20 \%$ oleic acid; (b) and (c) the same as (a) on progressively expanded applied field scales.

to that of magnetite $(32.87 \mathrm{emu} / \mathrm{g})$, opposite to expectation. This is attributed to the presence of nonstoichiometry and a thicker "dead layer" in the magnetite particles compared to those of maghemite [43]. Nonstoichiometry implies partial oxidation of magnetite to maghemite, as already observed in the Mössbauer spectra. Thus, our Mössbauer and magnetization studies indicate that the nanoparticles marketed as $\mathrm{Fe}_{3} \mathrm{O}_{4}$ are actually non-stoichiometric, partially oxidized magnetite.

3.5. SAR Measurements. In order to test and compare the particles' efficacy as hyperthermia agents for application in biomedicine, the change in sample temperature as a function of exposed time to the alternating magnetic field for the $\gamma-\mathrm{Fe}_{2} \mathrm{O}_{3}$ and $\mathrm{Fe}_{3} \mathrm{O}_{4}$ based ferrofluids in hexane were measured, as shown in Figures 11(a) and 11(b). Initial slopes, $(\Delta T / \Delta t)_{\text {initial }}$, over the first 60 seconds were measured for 


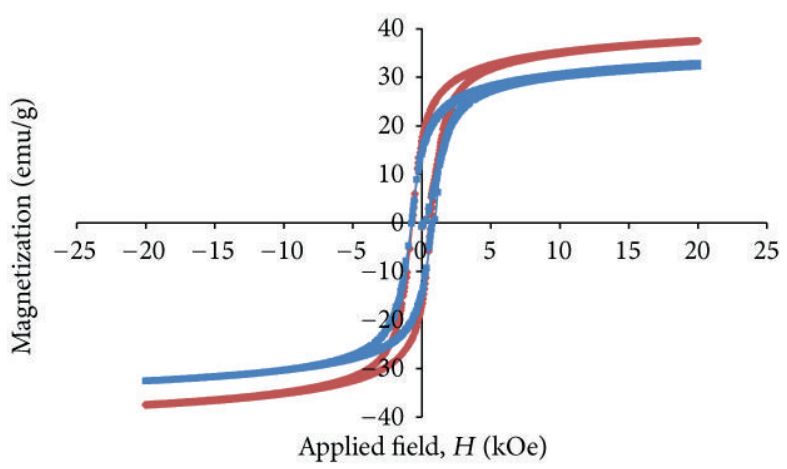

(a)

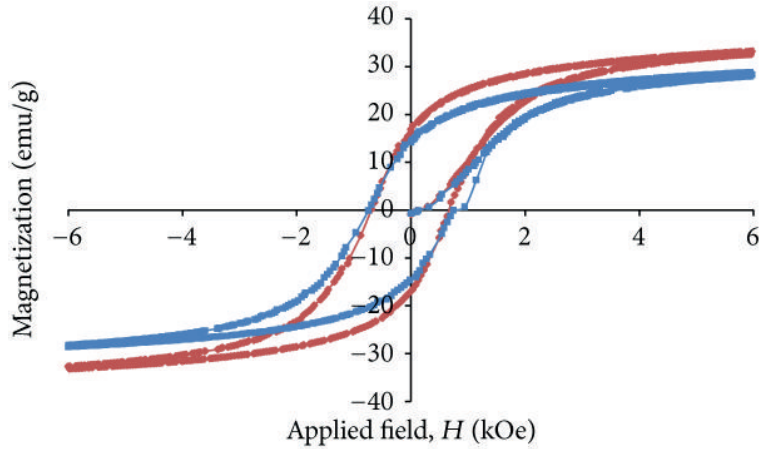

(b)

Figure 10: (a) Magnetization data at $2 \mathrm{~K}$ for $\gamma$ - $\mathrm{Fe}_{2} \mathrm{O}_{3}$ (red) and $\mathrm{Fe}_{3} \mathrm{O}_{4}$ (blue) nanoparticles $6 \mathrm{hr}$ milled in hexane with $20 \%$ oleic acid, (b) the same as (a) on an expanded applied field scale.

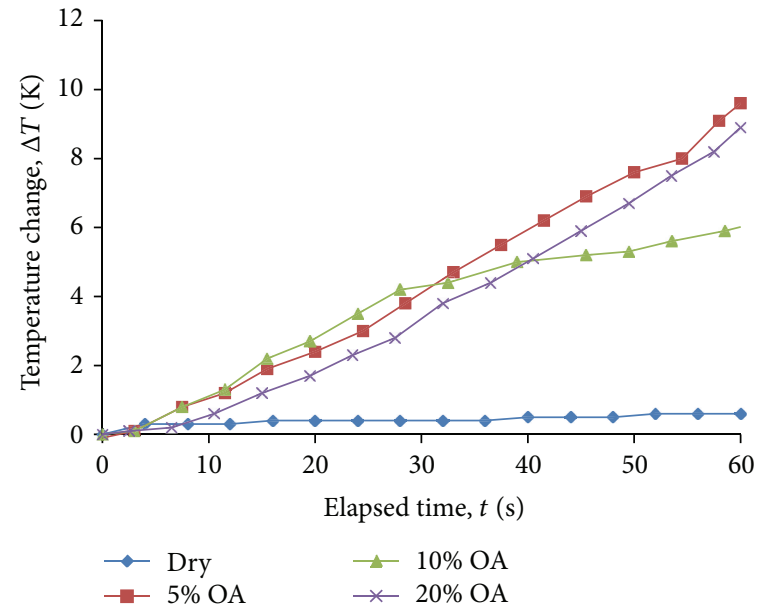

(a)

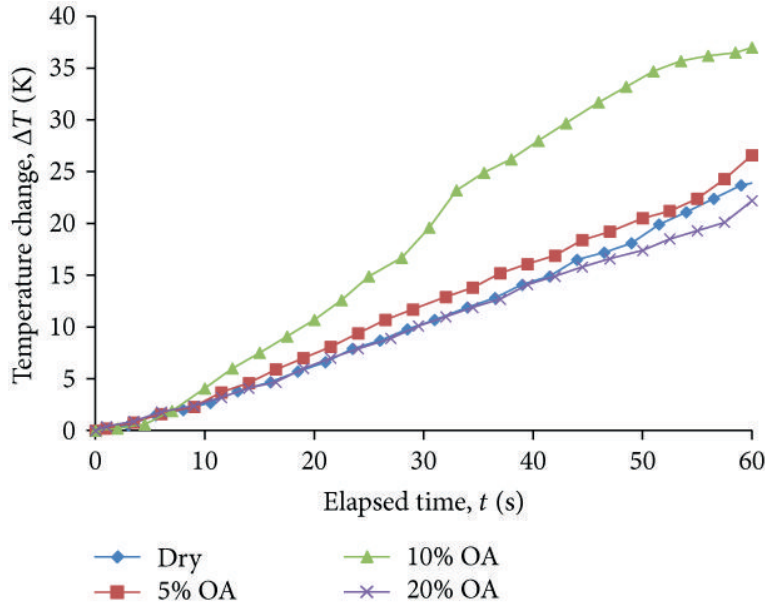

(b)

Figure 11: Change in sample temperature versus elapsed time of AC field exposure for: (a) $\gamma-\mathrm{Fe}_{2} \mathrm{O}_{3}$ and (b) $\mathrm{Fe}_{3} \mathrm{O}_{4}$ nanoparticle preparations milled dry or in hexane with various concentrations of oleic acid as indicated (note the difference in the vertical scales between (a) and (b)).

the evaluation of SAR according to (1). The calculated SAR values indicate the power dissipated as heat per gram of iron in the ferrofluid solution and are tabulated in Table 5.

In the calculation of SAR values using (1), the heat capacity of the sample, $c$, was determined by weighing the relative heat capacities of iron oxide $(0.653 \mathrm{~J} / \mathrm{g} \mathrm{K})$ [44], hexane $(2.26 \mathrm{~J} / \mathrm{g} \mathrm{K})$ and oleic acid $(2.046 \mathrm{~J} / \mathrm{g} \mathrm{K})$ [45]. In order to determine the values of $(\Delta T / \Delta t)_{\text {initial }}$, we computed the average change in temperature between the time at which heating began and that up until sixty seconds after that point. The calculated values of SAR correlate directly with the particles' relative efficiency for hyperthermia treatment. For the specific ferrofluids studied, nanoparticles marketed as $\mathrm{Fe}_{3} \mathrm{O}_{4}$ show a maximum value of SAR of $11.1 \mathrm{~W} / \mathrm{g}$ for the $10 \%$ oleic acid ferrofluid corresponding to a particle size of $9.4 \mathrm{~nm}$ diameter (Table 5). The $\gamma-\mathrm{Fe}_{2} \mathrm{O}_{3}$ ferrofluids do not exhibit such a maximum in the particle size range studied. According to Rosenweig's classic paper [46] these ferrofluids should exhibit a maximum SAR value at a specific particle size. However, the exact particle diameter for maximum SAR would depend on experimental parameters, such as, the particular carrier liquid chosen, the type of surfactant used, the amplitude, and frequency of the AC magnetic field driving the nanoparticles.

\section{Concluding Remarks}

The application of magnetic nanoparticles to medicine has never before been as crucial in scientific research as it is today. Even though we have limited our discussion to hyperthermia, iron oxide nanoparticles in biomedicine have widespread applications, both in the diagnosis and the treatment of disease. Iron oxide/ferrite nanoparticles are promising agents for magnetic resonance imaging (MRI) contrast enhancement, targeted drug delivery and gene therapy.

Iron-oxide nanoparticles have been used as MRI contrast agents due to their ability to shorten $\mathrm{T} 2$ proton relaxation times in the liver, spleen, and bone marrow, while new 
TABLE 5: SAR measurements for nanoparticle samples.

\begin{tabular}{lc}
\hline & SAR $(\mathrm{W} / \mathrm{g})$ \\
\hline$\gamma-\mathrm{Fe}_{2} \mathrm{O}_{3}$, dry $(16.2 \mathrm{~nm})$ & 0.126 \\
$\gamma-\mathrm{Fe}_{2} \mathrm{O}_{3}, 5 \%$ oleic acid $(13.7 \mathrm{~nm})$ & 5.365 \\
$\gamma-\mathrm{Fe}_{2} \mathrm{O}_{3}, 10 \%$ oleic acid $(7.9 \mathrm{~nm})$ & 5.257 \\
$\gamma-\mathrm{Fe}_{2} \mathrm{O}_{3}, 20 \%$ oleic acid $(7.3 \mathrm{~nm})$ & 6.685 \\
$\mathrm{Fe}_{3} \mathrm{O}_{4}$, dry $(15.3 \mathrm{~nm})$ & 5.813 \\
$\mathrm{Fe}_{3} \mathrm{O}_{4}, 5 \%$ oleic acid $(10.7 \mathrm{~nm})$ & 7.025 \\
$\mathrm{Fe}_{3} \mathrm{O}_{4}, 10 \%$ oleic acid $(9.4 \mathrm{~nm})$ & 11.084 \\
$\mathrm{Fe}_{3} \mathrm{O}_{4}, 20 \%$ oleic acid $(8.0 \mathrm{~nm})$ & 7.451 \\
\hline
\end{tabular}

research seeks the development of $\mathrm{T} 1$ relaxation agents in the form of iron-oxide based inorganic nanoparticles [4749]. Linked to specific ligands, iron oxide nanoparticles have been used in targeted molecular and cellular imaging [50]. The ability to manipulate magnetic nanoparticles with external magnets has enabled the direction of inhaled magnetic nanoparticles bound to pharmaceuticals in the form of aerosol droplets, coined "nanomagnetosols," through the respiratory system onto a targeted area of the lung [51]. Magnetic nanoparticles bound to nucleic acids have been guided via an external magnetic field gradient to deliver gene therapy via DNA transfection $[52,53]$, a process coined "magnetofection." Understanding how such nanoparticles respond to an external magnetic source and how they interact magnetically with one another is an active field of research aiming at expanding their biomedical applications.

In this communication we have demonstrated that ballmilling affords a direct, low cost way to uniform iron oxide nanoparticle production by physical means. Micromagnetic Mössbauer measurements at room temperature provided relative characterization of electronic structure and internal magnetization of two iron oxide systems in the nanometer regime, while macromagnetic studies via VSM probed the total magnetization and coercive behavior of the two iron oxide nanosystems. Our studies conclude that nanoparticles marketed as magnetite are non-stoichiometric partially oxidized magnetite. This is not surprising as due to their high surface to volume ratio oxidation of magnetite to maghemite can occur by oxygen diffusion into the nanoparticulate structure [37]. The severely broadened Mössbauer spectra, however, prevent further physical characterization of the nanoparticles and their detailed composition. For example the particles may be composed of a magnetite core surrounded by a shell of maghemite, or they may be amorphous composed of a continuous solid solution of $\mathrm{Fe}_{3-x} \mathrm{O}_{4-x}$ with $0 \leq x \leq 1$, as discussed earlier.

Under the particular experimental conditions used in our investigations and for the limited particle size range studied, the results indicated that $\mathrm{Fe}_{3} \mathrm{O}_{4}$ based ferrofluids derived from commercially available powders are slightly more efficient in releasing heat under an alternating magnetic field than those based on $\gamma$ - $-\mathrm{Fe}_{2} \mathrm{O}_{3}$, making the $\mathrm{Fe}_{3} \mathrm{O}_{4}$ based ferrofluids more suitable for hyperthermia applications. We note, however, that while this study concludes that the $9.4 \mathrm{~nm}$ diameter oleic acid covered $\mathrm{Fe}_{3} \mathrm{O}_{4}$ particles produce the highest SAR value $(11.084 \mathrm{~W} / \mathrm{g}$, Table 5), this value does not translate directly into properties of magnetite hyperthermia agents. Our particles were dispersed in hexane, rather than in water. As mentioned earlier, the nanoparticles must undergo a surfactant exchange process in order to render them hydrophilic and thus biocompatible [26-28]. Furthermore, in vivo, under the dynamic conditions of constant blood flow that cools the tissue [54], raising temperatures into the 40$46^{\circ} \mathrm{C}$ range will be more demanding compared to our static experimental conditions of SAR measurements. However, while the SAR values calculated for hydrophilic particles under biocompatible conditions may change, the relative SAR magnitudes of the particles tested in this study should remain true.

\section{Acknowledgments}

The authors thank Professor S. May for the help and use of his PPMS system in obtaining the magnetization measurements and Dr. W. Boyko for help in the use of the FTIR spectrometer. G. C. Papaefthymiou thanks the National Science Foundation, and P. Burnham thanks the department of Physics at Villanova University for support in undergraduate research.

\section{References}

[1] R. K. Gilchrist, R. Medal, W. D. Shorey, R. C. Hanselman, J. C. Parrot, and C. B. Taylor, "Selective inductive heating of lymph nodes," Annals of Surgery, vol. 146, no. 4, pp. 596-606, 1957.

[2] D. Ho, X. Sun, and S. Sun, "Monodisperse magnetic nanoparticles for theranostic applications," Accounts of Chemical Research, vol. 44, no. 10, pp. 875-882, 2011.

[3] D. C. F. Chan, D. B. Kirpotin, and P. A. Bunn Jr., "Synthesis and evaluation of colloidal magnetic iron oxides for the site-specific radiofrequency-induced hyperthermia of cancer," Journal of Magnetism and Magnetic Materials, vol. 122, no. 1-3, pp. 374378, 1993.

[4] A. Jordan, R. Scholz, P. Wust, H. Fähling, and R. Felix, "Magnetic fluid hyperthermia (MFH): cancer treatment with AC magnetic field induced excitation of biocompatible superparamagnetic nanoparticles," Journal of Magnetism and Magnetic Materials, vol. 201, no. 1-3, pp. 413-419, 1999.

[5] I. Hilger, K. Frühauf, W. Andrä, R. Hiergeist, R. Hergt, and W. A. Kaiser, "Heating potential of iron oxides for therapeutic purposes in interventional radiology," Academic Radiology, vol. 9, no. 2, pp. 198-202, 2002.

[6] Q. A. Pankhurst, J. Connolly, S. K. Jones, and J. Dobson, "Applications of magnetic nanoparticles in biomedicine," Journal of Physics D, vol. 36, no. 13, pp. R167-R181, 2003.

[7] Q. A. Pankhurst, N. K. T. Thanh, S. K. Jones, and J. Dobson, "Progress in applications of magnetic nanoparticles in biomedicine," Journal of Physics D, vol. 42, no. 22, Article ID 224001, 2009.

[8] C. H. Li, P. Hodgins, and G. P. Peterson, "Experimental study of fundamental mechanisms in inductive heating of ferromagnetic nanoparticles suspension $\left(\mathrm{Fe}_{3} \mathrm{O}_{4}\right.$ Iron Oxide Ferrofluid)," Journal of Applied Physics, vol. 110, no. 5, Article ID 054303, 2011. 
[9] S. Mornet, S. Vasseur, F. Grasset et al., "Magnetic nanoparticle design for medical applications," Progress in Solid State Chemistry, vol. 34, no. 2-4, pp. 237-247, 2006.

[10] S. P. Gubin, Ed., Magnetic Nanoparticles, John Wiley \& Sons, 2009.

[11] T. Hyeon, "Chemical synthesis of magnetic nanoparticles," Chemical Communications, vol. 9, no. 8, pp. 927-934, 2003.

[12] D. L. Leslie-Pelecky, V. Labhasetwar, and R. H. Kraus, "Nanobiomagnetics," in Advanced Magnetic Nanostructures, D. Sellmeyer and R. Shomski, Eds., Ch 15, pp. 461-489, Springer Science \& Business Media, New York, NY, USA, 2006.

[13] N. T. K. Thanh, Ed., Magnetic Nanoparticles: From Fabrication to Clinical Applications, CRC Press, 2012.

[14] A. G. Roca, M. P. Morales, K. O'Grady, and C. J. Serna, "Structural and magnetic properties of uniform magnetite nanoparticles prepared by high temperature decomposition of organic precursors," Nanotechnology, vol. 17, no. 11, pp. 27832788, 2006

[15] A. G. Roca, J. F. Marco, M. Del Puerto Morales, and C. J. Serna, "Effect of nature and particle size on properties of uniform magnetite and maghemite nanoparticles," Journal of Physical Chemistry C, vol. 111, no. 50, pp. 18577-18584, 2007.

[16] R. Hiergeist, W. Andrä, N. Buske et al., "Application of magnetite ferrofluids for hyperthermia," Journal of Magnetism and Magnetic Materials, vol. 201, no. 1-3, pp. 420-422, 1999.

[17] B. D. Cullity and C. D. Graham, Introduction to Magnetism and Magnetic Materials, John Wiley \& Sons, 2011.

[18] R. M. Cornell and U. Schwertmann, The Iron Oxides, VCH, New York, NY, USA, 1996.

[19] X. Batlle and A. Labarta, "Finite-size effects in fine particles: magnetic and transport properties," Journal of Physics D, vol. 35, no. 6, pp. R15-R42, 2002.

[20] T. P. Yadav, R. M. Yadav, and D. P. Singh, "Mechanical milling: a top down approach for the synthesis of nanomaterials and nanocomposites," Nanoscience and Nanotechnology, vol. 2, no. 3, pp. 22-48, 2012.

[21] G. F. Goya, "Handling the particle size and distribution of $\mathrm{Fe}_{3} \mathrm{O}_{4}$ nanoparticles through ball milling," Solid State Communications, vol. 130, no. 12, pp. 783-787, 2004.

[22] N. G. Akdogan, G. C. Hadjipanayis, and D. J. Sellmyer, "Anisotropic Sm-(Co,Fe) nanoparticles by surfactant-assisted ball milling," Journal of Applied Physics, vol. 105, no. 7, Article ID 07A710, 2009.

[23] D. L. Leslie-Pelecky and R. L. Schalek, "Effect of disorder on the magnetic properties of SmCo5," Physical Review B, vol. 59, no. 1, pp. 457-462, 1999.

[24] N. N. Greenwood and T. C. Gibb, Mössbauer Spectroscopy, Chapman Hall, London, UK, 1971.

[25] J. L. Neuringer and R. E. Rosensweig, "Ferrohydrodynamics," Physics of Fluids, vol. 7, no. 12, pp. 1927-1937, 1964.

[26] T. Zhang, J. Ge, Y. Hu, and Y. Yin, "A general approach for transferring hydrophobic nanocrystals into water," Nano Letters, vol. 7, no. 10, pp. 3203-3207, 2007.

[27] C. Zhang, T. Liu, J. Gao, Y. Su, and C. Shi, "Recent development and application of magnetic nanoparticles for cell labeling and imaging," Mini Reviews in Medicinal Chemistry, vol. 10, no. 3, pp. 193-202, 2010.

[28] N. A. Frey, S. Peng, K. Cheng, and S. Sun, "Magnetic nanoparticles: synthesis, functionalization, and applications in bioimaging and magnetic energy storage," Chemical Society Reviews, vol. 38, no. 9, pp. 2532-2542, 2009.
[29] R. Xu, Y. Zhang, M. Ma et al., "Measurement of specific absorption rate and thermal simulation for arterial embolization hyperthermia in the maghemite-gelled model," IEEE Transactions on Magnetics, vol. 43, no. 3, pp. 1078-1085, 2007.

[30] L. Zhang, R. He, and H.-C. Gu, "Oleic acid coating on the monodisperse magnetite nanoparticles," Applied Surface Science, vol. 253, no. 5, pp. 2611-2617, 2006.

[31] K. Petcharoen and A. Sirivat, "Synthesis and characterization of magnetite nanoparticles via the chemical co-precipitation method," Materials Science and Engineering B, vol. 177, no. 5, pp. 421-427, 2012.

[32] X. Wen, J. Yang, B. He, and Z. Gu, "Preparation of monodisperse magnetite nanoparticles under mild conditions," Current Applied Physics, vol. 8, no. 5, pp. 535-541, 2008.

[33] C. Kittel, "Theory of the structure of ferromagnetic domains in films and small particles," Physical Review, vol. 70, no. 11-12, pp. 965-971, 1946.

[34] C. Kittel, "Physical theory of ferromagnetic domains," Reviews of Modern Physics, vol. 21, no. 4, pp. 541-583, 1949.

[35] C. P. Bean and J. D. Livingston, "Superparamagnetism," Journal of Applied Physics, vol. 30, no. 4, pp. S120-S129, 1959.

[36] G. C. Papaefthymiou, E. Devlin, A. Simopoulos et al., "Interparticle interactions in magnetic core/shell nanoarchitectures," Physical Review B, vol. 80, no. 2, Article ID 024406, 2009.

[37] H. Topsøe, J. A. Dumesic, and M. Boudart, "Mössbauer spectra of stoichiometric and nonstoichiometric $\mathrm{Fe}_{3} \mathrm{O}_{4}$ microcrystals," Journal de Physique, vol. 35, no. 12, pp. 411-413, 1974.

[38] L.-Y. Zhang, H.-C. Gu, and X.-M. Wang, "Magnetite ferrofluid with high specific absorption rate for application in hyperthermia," Journal of Magnetism and Magnetic Materials, vol. 311, no. 1, pp. 228-233, 2007.

[39] P. Guardia, A. Labarta, and X. Batlle, "Tuning the size, the shape, and the magnetic properties of iron oxide nanoparticles," Journal of Physical Chemistry C, vol. 115, no. 2, pp. 390-396, 2011.

[40] P. Allia, M. Coisson, M. Knobel, P. Tiberto, and F. Vinai, "Magnetic hysteresis based on dipolar interactions in granular magnetic systems," Physical Review B, vol. 60, no. 17, pp. 1220712218, 1999.

[41] J. M. D. Coey, "Noncollinear spin arrangement in ultrafine ferrimagnetic crystallites," Physical Review Letters, vol. 27, no. 17, pp. 1140-1142, 1971.

[42] G. C. Papaefthymiou, "Nanoparticle magnetism," Nano Today, vol. 4, no. 5, pp. 438-447, 2009.

[43] C. Pereira, A. M. Pereira, C. Fernandes et al., "Superparamagnetic $\mathrm{MFe}_{2} \mathrm{O}_{4}(\mathrm{M}=\mathrm{Fe}, \mathrm{Co}, \mathrm{Mn})$ nanoparticles: tuning the particle size and magnetic properties through a novel one-step coprecipitation route," Chemistry of Materials, vol. 24, no. 8, pp. 1496-1504, 2012.

[44] http://www.thermtest.com/material-property-search/.

[45] C. Yaws, Chemical Properties Handbook: Physical, Thermodynamics, Environmental Transport, Safety \& Health Related Properties For Organic \& Inorganic Chemicals, Technology \& Engineering, McGraw-Hill Education, 1999.

[46] R. E. Rosenweig, "Heating magnetic fluid with alternating magnetic field," Journal of Magnetism and Magnetic Materials, vol. 252, pp. 370-374, 2002.

[47] H. B. Na, I. C. Song, and T. Hyeon, "Inorganic nanoparticles for MRI contrast agents," Advanced Materials, vol. 21, no. 21, pp. 2133-2148, 2009. 
[48] Y. Gossuin, P. Gillis, A. Hocq, Q. L. Vuong, and A. Roch, "Magnetic resonance relaxation properties of superparamagnetic particles," Nanomedicine and Nanobiotechnology, vol. 1, no. 3, pp. 299-310, 2009.

[49] Y.-W. Jun, Y.-M. Huh, J.-S. Choi et al., "Nanoscale size effect of magnetic nanocrystals and their utilisation for cancer diagnosis via magnetic resonance imaging," Journal of the American Chemical Society, vol. 127, no. 16, pp. 5732-5733, 2005.

[50] J. W. M. Bulte and D. L. Kraitchman, "Iron oxide MR contrast agents for molecular and cellular imaging," $N M R$ in Biomedicine, vol. 17, no. 7, pp. 484-499, 2004.

[51] P. Dames, B. Gleich, A. Flemmer et al., "Targeted delivery of magnetic aerosol droplets to the lung," Nature Nanotechnology, vol. 2, no. 8, pp. 495-499, 2007.

[52] B. B. Yellen, M. Chorny, I. Fishbein et al., "Nanoparticle Mediated Gene Delivery to Magnetized Implants," Molec. Therapy, vol. 11, p. S355, 2005.

[53] J. Dobson, "Gene therapy progress and prospects: magnetic nanoparticle-based gene delivery," Gene Therapy, vol. 13, no. 4, pp. 283-287, 2006.

[54] H. Barcroft and O. G. Edholm, "Temperature and blood flow in the human forearm," Journal of Physiology, vol. 104, pp. 366-376, 1946. 

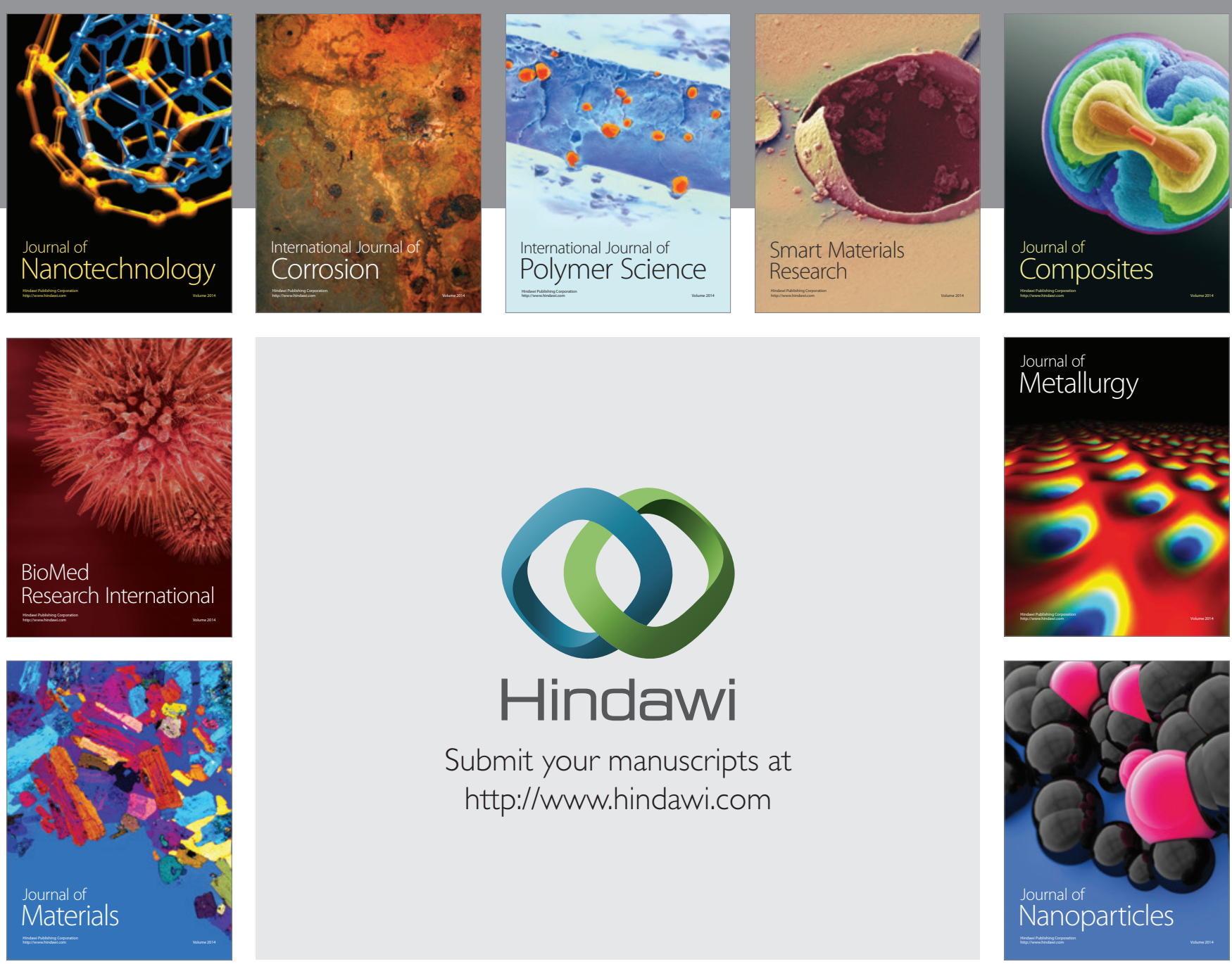

Submit your manuscripts at http://www.hindawi.com
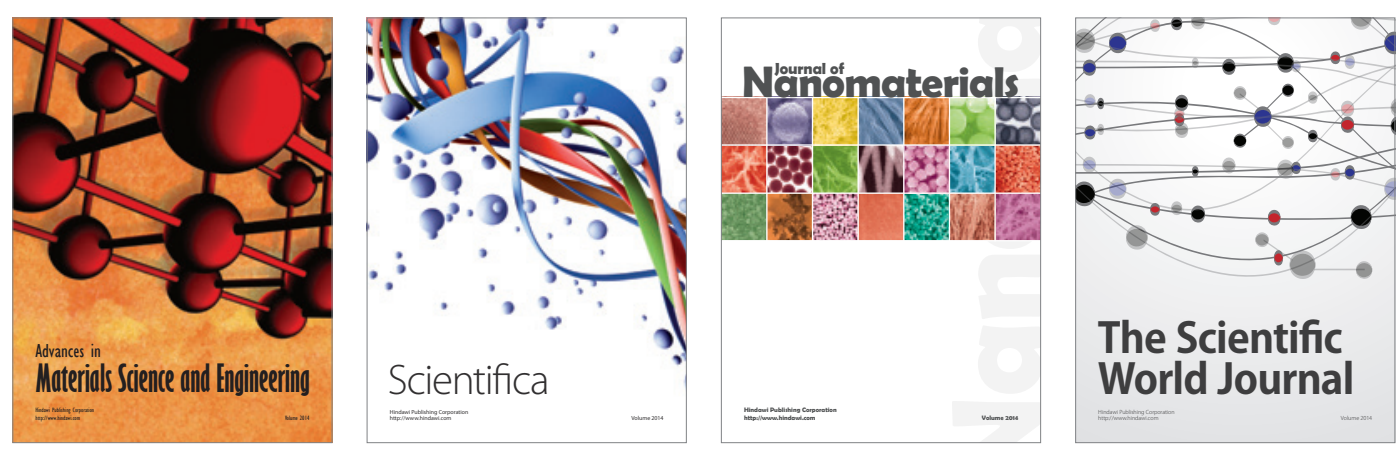

\section{The Scientific World Journal}
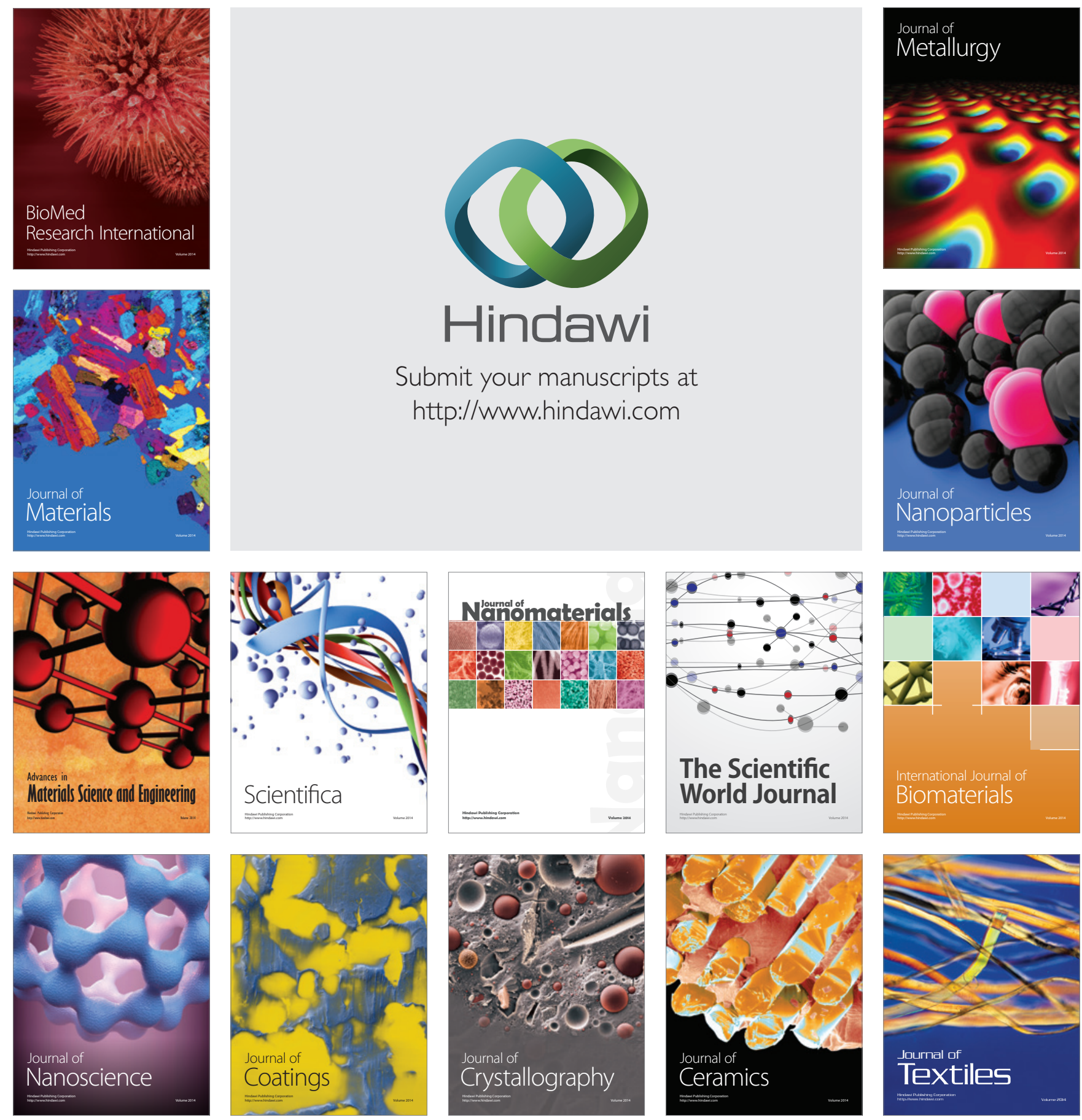